\title{
Tactile Cortical Responses and Association with Tactile Sensitivity in Young Children on the Autism Spectrum
}

\section{Svenja Espenhahn ( $\square$ svenja.espenhahn@ucalgary.ca )}

University of Calgary Cumming School of Medicine https://orcid.org/0000-0002-4460-3853

\section{Kate J. Godfrey}

University of Calgary Cumming School of Medicine

\section{Sakshi Kaur}

University of Calgary Cumming School of Medicine

\section{Maia Ross}

University of Calgary Cumming School of Medicine

\section{Carly McMorris}

University of Calgary The Werklund School of Education

\section{Filomeno Cortese}

University of Calgary Cumming School of Medicine

Charlene Wright

University of Calgary

\section{Kara Murias}

University of Calgary Cumming School of Medicine

\section{Deborah Dewey}

University of Calgary Cumming School of Medicine

\section{Andrea B. Protzner}

University of Calgary Faculty of Arts

\section{Adam McCrimmon}

University of Calgary The Werklund School of Education

\section{Signe Bray}

University of Calgary Cumming School of Medicine

\section{Ashley D. Harris}

University of Calgary Cumming School of Medicine

\section{Research}

Keywords: somatosensory-evoked potentials, ERP, EEG, adaptation, tactile stimulation, tactile sensitivities, autism, children 
Posted Date: December 1st, 2020

DOI: https://doi.org/10.21203/rs.3.rs-115417/v1

License: (c) (i) This work is licensed under a Creative Commons Attribution 4.0 International License. Read Full License

Version of Record: A version of this preprint was published at Molecular Autism on April 1st, 2021. See the published version at https://doi.org/10.1186/s13229-021-00435-9. 


\section{Abstract}

Background: Unusual responses to sensory stimuli are frequently reported in individuals on the autism spectrum (AS). Despite the early emergence of sensory features (<age 3) and their potential impact on development and quality of life, little is known about the neural mechanisms underlying sensory sensitivities in early childhood autism.

Methods: Here, we used electroencephalography (EEG) to investigate tactile cortical processing in young children aged 3-6 years with autism and in neurotypical (NT) children. Scalp EEG was recorded from 33 children with autism, including those with low cognitive and/or verbal abilities, and 45 age- and sexmatched NT children during passive tactile fingertip stimulation. We compared properties of early and later somatosensory-evoked potentials (SEPs) and their adaptation with repetitive stimulation between autistic and NT children and assessed whether these neural measures are linked to "real-world" parentreported behavioral tactile sensitivity.

Results: As expected, we found elevated behavioral tactile sensitivity in children on the autism spectrum. Our findings indicated no differences in amplitude or latency of early and mid-latency somatosensoryevoked potentials (P50, N80, P100), nor adaptation between autistic and NT children. However, latency of later processing of tactile information (N140) differed between young children with and without autism, suggesting faster processing speed in young autistic children. Further, correlational analyses and exploratory analyses using tactile phenotype as a grouping variable found that enhanced early neural responses were associated with greater behavioral tactile sensitivity in autism.

Limitations: The relatively small sample size and the inclusion of a broad range of autistic children (e.g., with low cognitive and/or verbal abilities) may have limited our power to detect subtle group differences and associations. Hence, replications are needed to verify these results.

Conclusions: Our findings suggest that electrophysiological somatosensory cortex processing measures may be indices of "real-world" tactile sensitivity in early childhood autism. Together, these findings advance our understanding of the neurophysiological mechanisms underlying tactile sensitivity in early childhood autism and, in the clinical context, may have therapeutic implications.

\section{Introduction}

Autism spectrum (AS) describes a heterogeneous neurodevelopmental condition diagnosed based on social communication deficits and restricted, repetitive behaviors (American Psychiatric Association, 2013). However, the presence of sensory difficulties has recently been recognized as a core feature of autism (in the DSM-5; (American Psychiatric Association, 2013)), consistent with estimates suggesting that over $90 \%$ of individuals on the autism spectrum show unusual responses to sensory stimuli that persist across age (Ben-Sasson et al., 2009; Leekam et al., 2007; Tomchek and Dunn, 2007). However, sensory difficulties in autism are highly heterogeneous, including both hyper- and hypo-sensitivity that limit everyday functioning (Ben-Sasson et al., 2009; Leekam et al., 2007; Thye et al., 2018; Tomchek and 
Dunn, 2007). Understanding the neurophysiological processes underlying sensory difficulties may yield crucial insights into the condition, and may also have clinical implications for improving therapies and creating sensory-friendly environments for individuals with autism.

Interest in sensory processing differences in autism has surged, with many studies focusing on auditory and visual modalities, likely due to their relevance for communication (for review see (Marco et al., 2011)). Far less work has been done to understand unusual tactile responses in autism (e.g., avoiding light touch as occurs with grooming and from clothing or seeking out pressure stimuli), despite the central role of touch in early development of social, communication and motor abilities (Cascio, 2010; Thye et al., 2018). It is during the early years of life that tactile difficulties emerge (< age 3 years) (Leekam et al., 2007; McCormick et al., 2016) and may exacerbate the core social communicative and behavioral features observed in autism (Foss-Feig et al., 2012; Robertson and Baron-Cohen, 2017).

To date, neuroimaging studies in autism have identified differences in somatotopic mapping (Coskun et al., 2009) and reduced evoked responses to tactile stimulation in somatosensory cortex (Cascio et al., 2012; Gaetz et al., 2017; Marco et al., 2012). However, other studies have reported normal (Cascio et al., 2015; Coskun et al., 2013; Demopoulos et al., 2017; Ganesan et al., 2016; Khan et al., 2015) or even enhanced (Kaiser et al., 2016; Khan et al., 2016; Miyazaki et al., 2007) somatosensory responses. Neural responses to touch have also been related to tactile features in older children and adolescents with autism (Cascio et al., 2015; Marco et al., 2012).

Another area that impacts tactile processing is how neural responses adapt to repeated stimulation. This neurophysiological process, whereby the neural response strength decreases with repeated stimulation, is thought to "filter" out irrelevant stimuli and conserve attentional resources (Wang et al., 2010; Wark et al., 2008). In the tactile domain, behavioral (Puts et al., 2014; Tannan et al., 2008; Tommerdahl et al., 2007) and imaging (Green et al., 2015) observations suggest reduced adaptation in autism, but see (Cascio et al., 2008; Güçlü et al., 2007). Taken together, these findings suggest that altered inhibitory function, in line with the mechanistic proposal of imbalance between excitation and inhibition (Rubenstein and Merzenich, 2003) could explain some of the features of tactile sensitivity in autism.

However, work to date has focused mainly on adults or children older than 6 years due to practical and methodological challenges associated with testing young children. This leaves a gap in our knowledge of the neural basis of tactile processing in early childhood autism. Understanding tactile responses in this time period is of particular importance due to the early emergence of sensory difficulties in autism (Leekam et al., 2007; McCormick et al., 2016) and the emphasis on early intervention in promoting better quality-of-life outcomes for autistic children (Charman, 2019; Landa, 2018; Rogers et al., 2019; Sandbank et al., 2020).

Thus, the aim of this study was to assess tactile cortical processing in young children with autism aged 3-6 years using electroencephalography (EEG) and to determine if properties of somatosensory-evoked potentials (SEPs) are associated with "real-world" parent-reported tactile sensitivity. EEG is an ideal tool for challenging pediatric populations (e.g., easy to apply, no loud noises, less sensitive to movement than 
MRI) and provides insight into cortical processes with excellent temporal resolution, thus allowing us to understand which stages of tactile processing (early or later stages) might be aberrant in autism. Based on mixed previous findings (Cascio et al., 2015, 2012; Demopoulos et al., 2017; Gaetz et al., 2017; Ganesan et al., 2016; Marco et al., 2012), we expected SEP measures to be different in young children with autism compared to neurotypical (NT) children, but did not hypothesize a direction for differences. Further, given links between tactile cortical responses and tactile behavioral features in autism (Cascio et al., 2015; Marco et al., 2012), we hypothesized that SEP measures would be associated with parentreported tactile sensitivity.

\section{Methods}

\subsection{Participants}

Thirty-three young children with autism aged 3-6 years were initially recruited from the Owerko Neurodevelopmental Disorder Recruitment database and the local community. All autistic children had a prior clinician diagnosis, which often included the administration of the Autism Diagnostic Observation Schedule (ADOS) (Lord et al., 2000). Clinician diagnosis was supported by parent reports on the Social Responsiveness Scale, Second Edition (SRS-2), a quantitative measure of clinical autistic traits (Constantino and Gruber, 2005). When an autistic child scored below the cut-off on the SRS-2 ( $\leq 59 \mathrm{~T})$, an ADOS was administered by a research-reliable rater to confirm diagnosis. Exclusion criteria included known genetic etiology of autism (e.g., Fragile $X$ syndrome, tuberous sclerosis), seizures at the time of study entry, a history of major head trauma or loss of consciousness of $>5 \mathrm{~min}$ and/or neurologic disease. Four children with autism had also been diagnosed with attention-deficit/hyperactivity disorder (ADHD), one global developmental delay (GDD) and one was born prematurely at 27 weeks gestational age. Two children were receiving medication used to treat ADHD (e.g., Strattera, Intuniv, Vyvanse). These medications were withheld for at least 24 hours prior to the study visit (when possible, and with parental consent). Excluding all autistic participants with comorbidities and pre-term birth $(\mathrm{N}=6)$ did not change the results reported here and so these participants were included in the analyses.

Forty-five age- and sex-matched NT children were recruited using the Healthy Infants and Children Clinical Research Program (HICCUP) and community advertisements. NT participants were excluded if they had a history of neurological, psychiatric or neurodevelopmental disease, a history of major head trauma or loss of consciousness of $>5 \mathrm{~min}$, were born prematurely ( $<37$ weeks), were using psychotropic medications, or scored above the cut-off on the SRS-2. There were no significant differences between groups in age, sex or handedness (as assessed by a parent questionnaire adapted from (Kastner-Koller et al., 2007)) (see Table 1).

General cognitive ability of all children was measured using the brief version of the Wechsler Non-Verbal (WNV) Scale of Ability (Naglieri and Brunnert, 2009), which allows for the assessment of individuals with limited language skills. In all but 3 autistic children, who did not understand and/or respond to non-verbal instructions, a non-verbal IQ estimate was obtained (Table 1). 
The study was approved by the University of Calgary Conjoint Health Research Ethics Board (REB160576). Written informed consent in accordance with the Declaration of Helsinki was obtained from a parent/guardian of each child who themselves assented to testing.

\subsection{Tactile sensitivity measures}

Parents completed the Child Sensory Profile 2 (CSP-2; (Dunn, 1999)), a standardized parent-report questionnaire that measures sensory processing patterns in everyday life. For each item, parents were asked to rate their child's response to a sensory experience on a 5-point Likert scale ranging from 'Almost Never' (1) to 'Almost Always' (5). While the CSP-2 addresses multiple sensory domains (e.g., visual, auditory, oral), this study focused exclusively on the tactile domain. We derived three measures representing overall behavioral tactile sensitivity as well as tactile hyper- and hypo-sensitivity. Specifically, scores for all questions related to the tactile domain were summed to yield a behavioral tactile sensitivity measure (CSP-2 questions 16-26). To explore whether tactile hyper- or hypo-sensitivity relate to SEP measures, scores for questions related to sensitivity and avoiding (e.g., "My child shows an emotional or aggressive response to being touched.") were summed to yield a tactile hyper-sensitivity measure (CSP-2 questions 16-20), while scores for questions related to registration and seeking (e.g., "My child touches people and objects more than same-aged children.") were summed to yield a tactile hypo-sensitivity measure (CSP-2 questions 21-26). Please note that each of these two behavioral profiles were made up of different CSP-2 quadrants within the tactile domain and do not reflect opposite ends of the same scale. Thus, for all three behavioral tactile sensitivity measures, higher scores indicate more sensory difficulties.

\subsection{Procedure}

Electroencephalography (EEG) was recorded while participants received passive tactile stimulation to the fingertips (index and middle finger) of their right hand (Fig. 1). Prior to the testing session, parents were interviewed regarding their child's communication, behavior and interests in order to individually tailor the testing environment and session to be as comfortable as possible for each child. A video of a child participating in EEG testing was sent to parents to review with their child prior to the session (YouTube: "What is a research EEG like?"). During the testing session, behavioral strategies were used to support EEG data acquisition, supported by an occupational therapist (C.W.). These strategies included parents as partners (e.g., working with parents to achieve child participation through shared decision-making), visual supports (e.g., pictures used to communicate and interact with autistic children), desensitization (e.g., gradual exposure to a feared or aversive stimulus until emotional response is tolerable), and individualized reinforcement (e.g., rewards that are motivating for the specific individual). To further increase compliance during the EEG recording (Gabrielsen et al., 2018; Vanderwal et al., 2015), participants watched a movie of their or their parent's choice on a 15-inch HD monitor (Dell Inspiron 15 3000 Series, display dimensions $1366 \times 768 \mathrm{~mm}$, resolution $1366 \times 768$ pixels, refresh rate $60 \mathrm{~Hz}$ ) with the volume adjusted to each participant's personal preference level. Importantly, we have previously shown that movie-watching does not modulate properties of somatosensory-evoked potentials (SEPS) (Espenhahn et al., 2020). Breaks were included as required, including briefly pausing the delivery of 
stimuli to suit child comfort. Together, these strategies enabled successful EEG data collection from more than $80 \%$ of children on the autism spectrum and $95 \%$ of NT children in this challenging age range, including those with low cognitive and/or verbal abilities who are often excluded from neuroimaging research (see Results section for more details).

\subsubsection{Tactile EEG task}

Participants received passive tactile stimulation to their right index and middle fingers simultaneously. No behavioral responses to the stimuli were required. Somatosensory mechanical stimuli were generated using a customized Brain Gauge two-digit vibrotactile stimulator (Cortical Metrics, North Carolina, USA) (Fig. 1A). Stimulus delivery was controlled by a computer running Presentation software (Neurobehavioral Systems, Berkeley, CA, USA). All stimuli were suprathreshold (frequency $25 \mathrm{~Hz}$, amplitude $300 \mu \mathrm{m}$, duration $40 \mathrm{~ms}$ ) and delivered to the glabrous skin of the fingertips using cylindrical probes ( $5 \mathrm{~mm}$ in diameter). Tactile stimulation consisted of four successive blocks with fifty repetitions of a 6-stimulus train in each block (300 stimuli in total in each block). Each train of 6 stimuli was separated from the next by an interval of $5 \pm 0.5 \mathrm{~s}$ (measured from the last stimulus in a train to the first stimulus of the preceding train). Within each block, the inter-stimulus interval (ISI) within the trains of tactile stimulation was constant and set to either $1050 \mathrm{~ms}$ or $150 \mathrm{~ms}$ (Fig. 1B). The order of the long (1050 ms) and short (150 ms) ISI blocks was counterbalanced. Shorter ISIs, in which stimuli are presented close together in time, typically lead to a reduction in the cortical response amplitude, hereafter referred to as adaptation (Andrade et al., 2016; Angel et al., 1985; Uppal et al., 2016). Thus, while the $1050 \mathrm{~ms}$ ISI was used to assess somatosensory processing of individual stimuli, the $150 \mathrm{~ms}$ ISI allowed us to assess somatosensory adaptation. The duration of the somatosensory stimulation was $\sim 15$ minutes and an experimenter monitored each child throughout to ensure compliance and provided verbal support when necessary.

\subsubsection{EEG data acquisition}

Scalp EEG was recorded at $1000 \mathrm{~Hz}$ using a 64-electrode (equidistant) geodesic sensor net (Electrical Geodesic Inc., Oregon, USA) soaked in an electrolyte solution. All electrodes were spaced evenly and symmetrically to cover the scalp. The impedance level was kept below $50 \mathrm{k} \Omega$ and the EEG signal was referenced to $\mathrm{Cz}$ during recording. The timing of the first tactile stimulus in a train was marked in the simultaneous EEG recording, with separate markers for each ISI condition (long, short).

\subsection{EEG data analysis}

\subsubsection{Pre-processing}

EEG data pre-processing and analysis were performed using EEGLAB (version 14) (Delorme and Makeig, 2004), ERPLAB Toolbox (version 7) (Lopez-Calderon and Luck, 2014) and additional scripts written in Matlab (version R2017b). The raw EEG signal was filtered using a high-pass filter at $0.1 \mathrm{~Hz}$ and a lowpass filter at $45 \mathrm{~Hz}$, downsampled to $250 \mathrm{~Hz}$, and re-referenced to the average signal of all electrodes. 
Excessively noisy EEG electrodes (mean $1 \pm 2$ electrodes, range $0-6$ electrodes) were removed and interpolated prior to re-referencing so as to not include excessive noise in the common average. Ocular artifacts were corrected by applying independent component analysis (ICA) as implemented in EEGLAB (excluding the interpolated electrodes). Artifact independent components (ICs) were visually identified using SASICA (Chaumon et al., 2015) as a guideline. An average of 3.2 \pm 1 ICs (range 2-6 ICs) ocular artifacts were removed, and the number of ICs did not differ between groups $\left[F_{(67))}=-1.62, p=0.111\right]$.

The continuous EEG signal was epoched from - 50 ms to 500 ms relative to stimulus onset $(0 \mathrm{~ms})$ and baseline corrected using the 50 ms pre-stimulus period. EEG trials were visually inspected and trials containing residual artifacts (e.g., due to movement or talking) were removed. The average number of trials used to compute SEPs was $210 \pm 34$ for the AS group and $228 \pm 24$ for the NT group. As expected, the AS group had a lower trial retention rate for both the long ISI $\left[\mathrm{t}_{(39.39)}=2.54, p=0.015\right]$ and short ISI $\left[\mathrm{t}_{(67)}=\right.$ 2.19, $p=0.032$ ] trials compared to the NT group. In all cases, a minimum of 150 trials were evaluable (AS: range 151-258; NT: range 187-277). Trial retention was unrelated to IQ or age (both $p>0.5$ ). From our observations and previous findings (DiStefano et al., 2019), it appears that the participant's affective state influenced EEG trial retention (e.g., children who were upset or irritable prior to the start of testing were less compliant). To verify that trial retention rate did not influence our findings, we re-ran our analyses including the number of remaining trials as a covariate, which did not change the results reported here.

\subsubsection{SEP analysis}

The artifact-free EEG data were averaged over trials and participants. Visual inspection of the grandaverage topography and SEP traces for both groups showed early and mid-latency SEP responses P50 (30-55 ms), N80 (55-80 ms), and P100 (80-125 ms), as well as later responses N140 (150-210 ms) and P300 (270-300 ms; also called late positive component), which were all most prominent at electrodes situated above the somatosensory cortex contralateral to the stimulated fingers (Allison et al., 1992, 1991, 1989a; Bruyant et al., 1993; Desmedt and Tomberg, 1989; Hämäläinen et al., 1990; Polich, 2007). Given that the somatosensory cortex has been suggested to be different in individuals with autism (Coskun et al., 2009), individual regions of interest (ROIs) were selected based on electrodes that showed a major positive peak in the 30-55 ms and 80-125 ms time windows. In addition, regions beyond the somatosensory cortex, such as the bilateral frontal lobes, have been shown to be active during the later stages of tactile processing (Allison et al., 1989b, 1991, 1992; Desmedt and Robertson, 1977). For this reason, two additional responses, P190 (150-240 ms) and N300 (280-400 ms), were evaluated from a $\mathrm{ROI}$ over the bilateral frontal cortex. For each participant, 5 electrodes were selected and averaged for each ROI (somatosensory and frontocentral) from SEP data averaged over the respective time windows. The same ROls were used for all analyses for that participant. The topographic plot in Fig. 3A and B (top panel) shows a strong overlap across participants in the electrodes selected. Selected time windows applied to all participants and ISIs, and were not adjusted individually. 
For each individual participant, the peak latency and mean amplitude for each SEP response was derived from the respective time windows and individual ROls to investigate potential differences in the speed and strength of processing between groups.

In addition, we derived the mean amplitude difference between the long (ISI of $1050 \mathrm{~ms}$ ) and short (ISI of $150 \mathrm{~ms}$ ) ISI to characterise adaptation of SEP responses with repetitive stimulation. Note that a quantitative assessment of adaptation was only possible for the early and mid-latency SEP responses (P50, N80, P100) as the time window for later SEP responses overlapped with the SEP to the subsequent stimulus in the short ISI.

\subsection{Statistical analysis}

Statistical analyses were performed using SPSS (IBM SPSS Statistics, Armonk, NY, USA) and customwritten Matlab routines. Effects of group (AS, NT) on tactile sensitivity measures (overall tactile sensitivity, hyper- and hypo-sensitivity) and properties of SEPs (peak latency and mean amplitude) were assessed using analysis of covariance (ANCOVA), with 'group' (2 levels: NT, AS) as a betweenparticipants factor. To assess group differences in the reduction in SEP amplitude with repetitive stimulation (adaptation), repeated-measures ANCOVAs with 'ISI' (2 levels: long ISI, short ISI) as withinparticipants factor and 'group' as between-participants factor were used. A significant interaction between 'ISI' and 'group' would suggest differences in the amount of adaptation between NT and AS groups. All analyses were controlled for age and sex given their influence on somatosensory cortical processing (Allison et al., 1984; Boor and Goebel, 2000; Pihko et al., 2009; Zhu et al., 1987). Whenever group differences were found, additional analyses controlling for non-verbal IQ were conducted. This was because lower IQ was clearly part of the autism phenotype in our data, so that including IQ as a covariate might have reduced the power to detect group differences.

All variables were tested for non-normality, the presence of which was addressed with bootstrapping (1000 bootstrapped samples) to estimate the $p$ value. Mauchly's test of sphericity was used to assess homogeneity of variance and a Greenhouse-Geiger correction was applied whenever Mauchly's test indicated a lack of sphericity.

To examine associations between our neural measures (latency, amplitude, and adaptation of SEP responses) and parent-reported tactile sensitivity, we used general linear models that included group by tactile sensitivity interactions, along with main effects and age and sex covariates. Significant statistical interactions, denoting group differences in associations, were followed up with partial correlations to test associations within groups. Uncorrected $p$ values are reported, together with multiple comparison (for all SEP responses within each $\mathrm{ROI}$ ) adjusted significance (using the false discovery rate (FDR) procedure (Benjamini and Hochberg, 1995)) held at $p_{\text {corr }}<0.05$. All data presented in the text and figures are represented as mean $\pm S D$ unless stated otherwise.

\section{Results}




\subsection{Participant characteristics}

Participant characteristics are shown in Table 1. The final sample included 28 autistic children and 41 NT children aged 3-6 years, which were matched for age, sex, and handedness (statistics and $p$ values are summarized in Table 1). The male-to-female ratio of participants with autism was 3.7:1. Of the 33 autistic children recruited, 5 children did not tolerate the EEG procedure. Of the 45 NT children recruited, 2 children did not tolerate the EEG procedure and another 2 children were excluded as they scored above the cut-off for autism on the SRS-2 (>59T). In the AS group, social symptom severity ranged from mild to severe based on the SRS-2 T-scores (7.1\% mild (60T-65T), 35.7\% moderate (66T-75T), and $57.1 \%$ severe $(\geq 76 T)$ ). As expected, the AS group had a lower average non-verbal IQ than the NT group, including 3 autistic children who completed the WNV but obtained a non-verbal IQ $<70$.

Table 1

Characteristics of study participants

\begin{tabular}{|llll|}
\hline \multicolumn{1}{|l}{ NT } & AS & Statistics \\
\hline $\mathrm{N}$ & 41 & 28 & \\
\hline Age [years] & $5.3 \pm 1.1$ & $5.4 \pm 1.1$ & $\mathrm{t}_{(67)}=-0.60, p=0.553$ \\
\hline Sex (M:F) & $28: 13$ & $22: 6$ & $X^{2}=0.88, p=0.348$ \\
\hline Handedness (R:L:A) & $38: 2: 1$ & $27: 0: 1$ & $X^{2}=1.46, p=0.481$ \\
\hline SRS-2 T-score & $45.1 \pm 5.8$ & $79.3 \pm 12.5$ & $\mathrm{t}_{(34.9)}=-13.60, \mathrm{p}<0.001$ \\
\hline Non-verbal IQ & $106.4 \pm 14.8$ & $95.8 \pm 21.9$ & $\mathrm{t}_{(33.0)}=2.92, \mathrm{p}=0.006$ \\
\hline Overall tactile sensitivity & $13.6 \pm 3.9$ & $25.4 \pm 9.1$ & $\mathrm{~F}_{(1,65)}=\mathbf{5 1 . 4 3 ,} \mathrm{p}<0.001$ \\
\hline Tactile hyper-sensitivity & $5.7 \pm 2.2$ & $10.6 \pm 4.6$ & $\mathrm{~F}_{(1,65)}=\mathbf{3 9 . 3}, \mathrm{p}<0.001$ \\
\hline $\begin{array}{l}\text { Tactile hypo-sensitivity } \\
\text { All participants had normal or corrected-to-normal vision. Group differences in sex and handedness } \\
\text { between children on the autism spectrum (AS) and a neurotypical }(N T) \text { comparison group were } \\
\text { assessed using chi-square test. Significant effects are indicated in bold. }\end{array}$ \\
\hline
\end{tabular}

In addition, children on the autism spectrum showed significantly more parent-reported tactile sensitivities (e.g., higher scores on the CSP-2 tactile domain) than the NT comparison group, as well as both greater hyper- and hypo-sensitivity (Table 1, Fig. 2A, B). According to the formal cut-off for the CSP-2 tactile domain score $(>21), 43 \%$ of the autistic children fell within the normal range, $18 \%$ had 'probable sensory differences' (>1 \& <2 SD, light grey area in Fig. 2A) and 39\% had 'definite differences' (>2 SD, dark grey area in Fig. 2A). In comparison, only $9 \%$ of NT children had 'probable sensory differences', while the rest fell within the normal range. Across groups, tactile hyper- and hypo-sensitivity were highly 
correlated [ $r=0.48, p<0.001], 95 \% \mathrm{Cl}[0.300 .70]]$. Within groups, these two behavioral profiles were significantly associated for the NT [ $r=0.34, p=0.028], 95 \% \mathrm{Cl}[0.020 .63]$, but not the AS group [ $r=0.21$, $p=0.281], 95 \% \mathrm{Cl}[-0.110 .56]$ (Fig. 2C).

\subsection{Somatosensory potentials and adaptation}

Grand-averaged SEP traces in response to passive tactile stimulation to the right fingers are shown in Fig. 3A (bottom) for the NT and AS groups, using the $1050 \mathrm{~ms}$ ISI. The early and mid-latency (P50, N80, P100) and later SEP responses (N140, P300) from contralateral somatosensory cortex are identifiable, with inverted polarity across the frontocentral scalp region (Fig. 3B, bottom). Over the bilateral frontal cortex, two later responses (P190, N300) are identifiable, reflecting the propagation of tactile information from posterior to anterior. The gross morphology and time course of the SEPs are highly similar between AS and NT groups. Individual ROls were selected for each participant, with Fig. 3A and B (top panel) showing the overlap of selected electrodes for each group.

\subsubsection{Early and mid-latency SEPs}

The first SEP response peaked $\sim 45 \mathrm{~ms}$ after stimulation over the contralateral somatosensory cortex, followed by a negative response at $\sim 70 \mathrm{~ms}$ and a major positive peak at $\sim 90 \mathrm{~ms}$ (Fig. 3A, C). Analysis of peak latency of these early SEP responses did not reveal a significant difference between AS and NT groups (F-statistics and $p$ values of all ANCOVAs are summarized in Table 2). Similarly, analysis of mean amplitude revealed no group differences for the P50, N80 and P100 components over the contralateral somatosensory cortex.

\subsubsection{Later SEPs}

For later SEP responses from contralateral somatosensory cortex, a negative response at $\sim 175$ ms was followed by a broad positivity 300 ms post-stimulation (Fig. 3A, C). Interestingly, the N140 latency statistically differed between groups (Table 2) and this group difference survived multiple comparison correction $\left(p_{\text {corr }}=0.035\right.$ ). Specifically, young children on the autism spectrum showed a shorter N140 peak latency $(172.81 \pm 19.5 \mathrm{~ms})$ relative to the NT group $(182.65 \pm 21.2 \mathrm{~ms})$ and including IQ as a covariate did not change this result $\left[F_{(1,63)}=5.81, p=0.019, \eta^{2}=0.084,95 \% \mathrm{Cl}\right.$ of effect size [0.01 0.23]]. Similarly, a significant group difference was identified for the N140 response amplitude, with the AS group exhibiting a smaller (i.e., less negative) N140 amplitude $(-0.62 \pm 1.47 \mu \mathrm{V})$ compared to the NT group $(-1.23 \pm 1.30 \mu \mathrm{V})$; however, this result did not survive multiple comparison correction $\left(p_{\text {corr }}=0.120\right)$. No significant differences in peak latency and mean amplitude between AS and NT groups were found for the somatosensory P300.

In addition, two later SEP responses were identified over the bilateral frontal cortex, including a positive peak at $\sim 190 \mathrm{~ms}$, followed by a broad negative response at $\sim 310 \mathrm{~ms}$ (Fig. 3B, C). Again, no significant differences in peak latency and mean amplitude between AS and NT groups were found for these frontal responses (Table 2). 
Table 2

ANCOVA results for differences in SEP responses between NT and AS groups.

Peak Latency

Mean Amplitude

Contralateral somatosensory ROI

$\begin{array}{lll}\text { P50 } & \mathrm{F}_{(1,65)}=0.06, p=0.801, \eta^{2}=0.001[00.06] & \mathrm{F}_{(1,65)}=1.73, p=0.193, \eta^{2}=0.026[00.14] \\ \text { N80 } & \mathrm{F}_{(1,65)}=0.39, p=0.533, \eta^{2}=0.006[00.09] & \mathrm{F}_{(1,65)}=0.10, p=0.753, \eta^{2}=0.002[00.07] \\ \text { P100 } & \mathrm{F}_{(1,65)}=1.60, p=0.210, \eta^{2}=0.024[00.13] & \mathrm{F}_{(1,65)}=0.00, p=0.994, \eta^{2}=0.000[00] \\ \text { N140 } & \mathrm{F}_{(1,64)}=7.70, \mathrm{p}=0.007, \eta^{2}=0.107[0.01 & \mathrm{F}_{(1,64)}=5.32, p=0.024^{*}, \eta^{2}=0.077[0.01 \\ & 0.26] & 0.22] \\ \text { P300 } & \mathrm{F}_{(1,65)}=0.41, p=0.525, \eta^{2}=0.006[00.09] & \mathrm{F}_{(1,65)}=0.02, p=0.892, \eta^{2}=0.000[00.04]\end{array}$

\section{Frontocentral ROI}

P190

$$
\mathrm{F}_{(1,65)}=0.02, p=0.771, \eta^{2}=0.001[00.04]
$$

$\mathrm{F}_{(1,65)}=0.54, p=0.465, \eta^{2}=0.008[00.10]$

N300

$$
\mathrm{F}_{(1,65)}=0.01, p=0.953, \eta^{2}=0.001[00.03]
$$

$\mathrm{F}_{(1,65)}=0.01, p=0.924, \eta^{2}=0.001[00.03]$

ANCOVA results controlling for age and sex. Significant effects at $p_{\text {corr }}<0.05$ are indicated in bold and * indicates effects at $p<0.05$ uncorrected that did not survive multiple comparison correction. Effect sizes ( $\eta^{2}$ ranging between 0 and 1$)$ and their $95 \%$ confidence intervals ( $\mathrm{Cl}$ in square brackets) are given.

\subsubsection{Adaptation effect}

Next, we compared the amount of adaptation early and mid-latency SEP responses exhibited with repetitive stimulation between AS and NT groups. A significant effect of ISI on the amplitude of the P50 was observed over the contralateral somatosensory cortex, with the short ISI leading to a significant reduction in mean amplitude across groups (F-statistics and $p$ values of all ANCOVAs are summarized in Table 3, Fig. 4); however, this effect was at trend level significance after multiple comparison correction $\left(p_{\text {corr }}=0.083\right)$. There was no effect of group or interaction between these two factors, indicating that the amount of adaptation of the P50 response was statistically comparable between AS and NT groups; however, a significant reduction in mean amplitude was only observed in the NT group $\left[\mathrm{t}_{(40)}=3.50, p=\right.$ $0.002]$ and not in the AS group $\left[\mathrm{t}_{(27)}=0.96, p=0.352\right]$. For the $\mathrm{N} 80$, a trend towards a significant amplitude difference between the short and long ISI was revealed, which did not survive multiple comparison correction, and no effect of group or interaction was present. There were no main effects (ISI, group) or interactions for the P100. 
Table 3

ANCOVA results for differences in adaptation effect between NT and AS groups.

Group ISI Interaction

Contralateral somatosensory ROI

\begin{tabular}{|c|c|c|c|}
\hline P50 & $\begin{array}{l}\mathrm{F}_{(1,65)}=0.30, p=0.583, \eta^{2}= \\
0.005[00.08]\end{array}$ & $\begin{array}{l}\mathrm{F}_{(1,65)}=4.49, p=0.038 *, \eta^{2}= \\
0.065[00.20]\end{array}$ & $\begin{array}{l}\mathrm{F}_{(1,65)}=1.61, p=0.209, \eta^{2}= \\
0.024[00.14]\end{array}$ \\
\hline N80 & $\begin{array}{l}\mathrm{F}_{(1,65)}=0.01, p=0.921, \mathrm{n}^{2}= \\
0.000[00.03]\end{array}$ & $\begin{array}{l}\mathrm{F}_{(1,65)}=3.83, p=0.055^{\star}, \eta^{2}= \\
0.056[00.19]\end{array}$ & $\begin{array}{l}\mathrm{F}_{(1,65)}=0.12, p=0.731, \mathrm{n}^{2}= \\
0.002[00.07]\end{array}$ \\
\hline P100 & $\begin{array}{l}\mathrm{F}_{(1,65)}=0.13, p=0.723, \mathrm{n}^{2}= \\
0.002[00.07]\end{array}$ & $\begin{array}{l}\mathrm{F}_{(1,65)}=1.32, p=0.255, \eta^{2}= \\
0.020[00.13]\end{array}$ & $\begin{array}{l}\mathrm{F}_{(1,65)}=0.34, p=0.56 \\
0.005[00.09]\end{array}$ \\
\hline
\end{tabular}

ANCOVA results controlling for age and sex. * indicates effects at $p<0.05$ uncorrected that did not survive multiple comparison correction. Effect sizes ( $\eta^{2}$ ranging between 0 and 1 ) and their $95 \%$ confidence intervals ( $\mathrm{Cl}$ in square brackets) are given.

\subsection{Associations between somatosensory potentials and tactile sensitivity}

Next, we investigated the relation of our neural measures (properties of SEPs and their adaptation) with parent-reported behavioral tactile sensitivity. Regressing overall behavioral tactile sensitivity and its interaction with group for each SEP response revealed significant group differences in the associations between behavioral tactile sensitivity and the amplitude of early and mid-latency SEP responses from contralateral somatosensory cortex [P50: $F_{(1,63)}=7.85, p=0.007$, effect size $\eta^{2}=0.111,95 \% \mathrm{Cl}$ of effect size [0.01 0.26]; N80: $F_{(1,63)}=5.54, p=0.022$, effect size $\eta^{2}=0.081,95 \% \mathrm{Cl}$ of effect size [0.01 0.23]; P100: $F_{(1,63)}=4.54, p=0.037$, effect size $\eta^{2}=0.067,95 \% \mathrm{Cl}$ of effect size [0 0.21]]. Including IQ as covariate did not change these results [P50: $F_{(1,62)}=8.86, p=0.004$, effect size $\eta^{2}=0.125,95 \% \mathrm{Cl}$ of effect size $[0.01$ 0.28]; N80: $F_{(1,62)}=5.88, p=0.018$, effect size $\eta^{2}=0.087,95 \% \mathrm{Cl}$ of effect size [0.01 0.23]; $P 100: F_{(1,62)}=$ $4.77, p=0.033$, effect size $\eta^{2}=0.071,95 \% \mathrm{Cl}$ of effect size [0 0.21$]$; however, only the group difference in the association between behavioral tactile sensitivity and the P50 response survived multiple comparison correction $\left(p_{\text {corr }}=0.035\right)$, while the other effects were trending (both $\left.p_{\text {corr }}=0.06\right)$. Specifically, NT children with a greater P50 response amplitude showed less tactile sensitivity [partial correlation: $r=-0.35, p=$ $0.029,95 \% \mathrm{Cl}[-0.61-0.12]]$, whereas autistic children showed a trend towards the opposite pattern, with greater P50 response amplitude related to more tactile sensitivity [partial correlation: $r=0.38, p=0.057$, $95 \% \mathrm{Cl}[-0.190 .75]$ ] (Fig. 5A). For the $\mathrm{N} 80$ and P100 components, a smaller (i.e., less negative) and greater response amplitude respectively, was related to more behavioral tactile sensitivity in autistic children [N80 partial correlation: $r=0.53, p=0.005,95 \% \mathrm{Cl}[0.110 .83]$; P100 partial correlation: $r=0.52, p=0.007,95 \%$ $\mathrm{Cl}[0.110 .82]$ ], but not NT children [N80 partial correlation: $\mathrm{r}=-0.21, p=0.208,95 \% \mathrm{Cl}[-0.460 .13] ; \mathrm{P} 100$ partial correlation: $r=-0.17, p=0.297,95 \% \mathrm{Cl}[-0.47$ 0.13]] (Fig. 5B, C). There were no group differences in associations between behavioral tactile sensitivity and adaptation of SEP responses. 
To gain further insight into the relation between behavioral tactile sensitivity and neural responses to touch, we next separately regressed tactile hyper-sensitivity and hypo-sensitivity and their interaction with group for each SEP response. There were significant group differences in the associations between tactile hypo-sensitivity and the P50 $\left[F_{(1,63)}=5.75, p=0.019\right.$, effect size $\eta^{2}=0.084,95 \% \mathrm{Cl}$ of effect size $[0.01$ 0.23]] and $P 100\left[F_{(1,63)}=4.56, p=0.037\right.$, effect size $\eta^{2}=0.067,95 \% \mathrm{Cl}$ of effect size [0 0.21]] amplitude from contralateral somatosensory cortex, which were at trend level significance after multiple comparison correction (both $p_{\text {corr }}=0.09$ ). Again, NT children with a greater P50 response amplitude showed less tactile hypo-sensitivity [partial correlation: $\mathrm{r}=-0.32, p=0.046,95 \% \mathrm{Cl}[-0.57,-0.06]]$, whereas autistic children showed the opposite pattern, with greater $\mathrm{P} 50$ response amplitude relating to more tactile hypo-sensitivity [partial correlation: $r=0.42, p=0.032,95 \% \mathrm{Cl}[0.06,0.69]$ ] (Fig. 5Ai). Similarly, a greater $\mathrm{P} 100$ response amplitude was related with more tactile hypo-sensitivity in autistic [partial correlation: $r=0.60, p=0.002$, $95 \% \mathrm{Cl}[0.08,0.79]]$, but not NT children [partial correlation: $r=-0.21, p=0.209,95 \% \mathrm{Cl}[-0.47,0.76]]$ (Fig. $5 \mathrm{Ci}$ ). There were no group differences in associations between tactile hyper-sensitivity and neural responses to touch.

\subsection{Exploratory analysis based on tactile sensitivity}

Lastly, we explored whether grouping individuals based on tactile phenotype rather than clinical autism diagnosis would be informative in elucidating neurophysiological differences. To this end, participants were regrouped based on behavioral tactile sensitivity (tactile typical (TT) vs tactile sensitive (TS)). One NT child was thus moved to the tactile sensitive group $(\mathrm{N}=17)$, and twelve autistic children were moved to the tactile typical group $(n=49)$. With this sensory-based regrouping, we again observed differences in the N140 response (Fig. 6, Table 4) such that the tactile sensitive group exhibited an earlier and smaller (i.e., less negative) N140 response (peak latency: $176.84 \pm 18.76 \mathrm{~ms}$; mean amplitude: $-0.60 \pm 1.60 \mu \mathrm{V}$ ) compared to the tactile typical group (peak latency: $179.23 \pm 21.60 \mathrm{~ms}$; mean amplitude: $-1.05 \pm 1.24 \mu \mathrm{V}$ ). Including IQ (TS group: 89.4 \pm 29.8 ; TT group: $100.9 \pm 27.5 ; \mathrm{t}_{(64)}=1.47, p=0.147$ ) as a covariate did not change these results [peak latency: $\mathrm{F}_{(1,60)}=4.09, p=0.048, \eta^{2}=0.064,95 \% \mathrm{Cl}$ of effect size [0 0.21]; mean amplitude: $\mathrm{F}_{(1,60)}=3.98, p=0.050, \eta^{2}=0.062,95 \% \mathrm{Cl}$ of effect size [0 0.20]]. However, these results did not survive multiple comparison correction (peak latency: $p_{\text {corr }}=0.087$, mean amplitude: $p_{\text {corr }}=0.088$ ). In addition, we found differences in the earlier N80 and P100 responses. Specifically, we observed an earlier and higher (i.e., less negative) N80 response in the tactile sensitive group (peak latency: $66.05 \pm 13.03 \mathrm{~ms}$; mean amplitude: $1.36 \pm 1.07 \mu \mathrm{V}$ ) compared to the tactile typical group (peak latency: $69.53 \pm 11.60 \mathrm{~ms}$; mean amplitude: $0.77 \pm 0.99 \mu \mathrm{V}$ ). For the $\mathrm{P} 100$, the tactile sensitive grouped showed a delayed and higher response (peak latency: $95.54 \pm 12.87 \mathrm{~ms}$; mean amplitude: $2.11 \pm 1.44 \mu \mathrm{V}$ ) compared to the tactile typical group (peak latency: $88.52 \pm 13.21 \mathrm{~ms}$; mean amplitude: $1.28 \pm 1.24 \mu \mathrm{V}$ ). However, none of these results survived multiple comparison correction ( $\mathrm{N} 80$ and P100 peak latency: $p_{\text {corr }}=0.087$, N80 and P100 mean amplitude: $p_{\text {corr }}=0.088$ ).

There were no significant differences in peak latency and mean amplitude between the tactile sensitive and tactile typical groups for any other somatosensory responses nor adaptation effects (all $p>0.2$ ). 
ANCOVA results for differences in SEP responses between tactile sensitive and tactile normal groups.

Peak Latency

\section{Contralateral somatosensory ROI}

\begin{tabular}{llll} 
P50 & $\mathrm{F}_{(1,62)}=1.15, p=0.289, \eta^{2}=0.018[00.13]$ & $\mathrm{F}_{(1,62)}=0.04, p=0.837, \eta^{2}=0.001[00.06]$ \\
N80 & $\mathrm{F}_{(1,61)}=4.42, p=0.040^{*}, \eta^{2}=0.068[00.21]$ & $\mathrm{F}_{(1,62)}=3.88, p=0.053^{*}, \eta^{2}=0.059[00.20]$ \\
P100 & $\mathrm{F}_{(1,62)}=3.93, p=0.052^{*}, \eta^{2}=0.060[00.20]$ & $\mathrm{F}_{(1,62)}=5.04, p=0.028^{*}, \eta^{2}=0.075[00.22]$ \\
\hline N140 & $\mathrm{F}_{(1,61)}=4.52, p=0.038^{*}, \eta^{2}=0.069[00.21]$ & $\mathrm{F}_{(1,61)}=4.18, p=0.045^{\star}, \eta^{2}=0.064[00.20]$ \\
\hline P300 & $\mathrm{F}_{(1,61)}=0.98, p=0.327, \eta^{2}=0.016[00.12]$ & $\mathrm{F}_{(1,62)}=1.42, p=0.238, \eta^{2}=0.022[00.13]$
\end{tabular}

\section{Frontocentral ROI}

P190

$$
F_{(1,62)}=0.20, p=0.657, \eta^{2}=0.003[00.08]
$$

$\mathrm{F}_{(1,62)}=0.95, p=0.334, \eta^{2}=0.015[00.12]$

N300

$$
F_{(1,62)}=2.91, p=0.093, \eta^{2}=0.045[00.17]
$$

$F_{(1,62)}=1.56, p=0.217, \eta^{2}=0.024[00.40]$

ANCOVA results controlling for age and sex. * indicates group differences at $p<0.05$ uncorrected that did not survive multiple comparison correction. Effect sizes ( $\eta^{2}$ ranging between 0 and 1 ) and their 95\% confidence interval ( $\mathrm{Cl}$ in square brackets) are given.

\section{Discussion}

The present study investigated tactile cortical responses in young children aged 3-6 years on the autism spectrum compared to NT children, and explored whether these neural responses relate to parent-reported behavioral tactile sensitivity. Despite elevated behavioral tactile sensitivity in autism, including greater hyper- and hypo-sensitivity, our findings indicated no differences in the early and mid-latency stages of tactile cortical processing nor adaptation between autistic and NT children. However, later processing of tactile stimulation differed between young children on the autism spectrum and NT children. We also found that somatosensory responses during the early stages of tactile processing were associated with behavioral tactile sensitivity in autism, suggesting that greater tactile sensitivity may result from enhanced neural responsiveness to touch in the early cortical processing stages.

Previous research investigating neural responses to tactile stimulation in children with autism older than 6 years has yielded mixed results, with some finding reduced (Gaetz et al., 2017; Marco et al., 2012) or normal evoked responses (Cascio et al., 2015; Demopoulos et al., 2017; Ganesan et al., 2016; Khan et al., 2015), while others observed enhanced responses (Kaiser et al., 2016; Khan et al., 2016; Miyazaki et al., 2007). Here, we studied early childhood (3-6 years) and found no differences in the early stages of tactile cortical processing between young children with and without autism. Similarly, we did not find 
evidence for impaired adaptation in young autistic children compared to NT children. As no other studies have investigated tactile processing in autism at such a young age, one potential explanation for these results may be that alterations in tactile cortical processing emerge only later in development (Gaetz et al., 2017; Khan et al., 2016; Marco et al., 2012). While this may seem counterintuitive given the early emergence of tactile difficulties in autism (Leekam et al., 2007; McCormick et al., 2016), including our autistic sample, it is in line with research on early brain development in autism suggesting that young children on the autism spectrum interact differently with their environment, which may affect their brain development (Dawson, 2008; Dawson et al., 2012). Specifically, tactile sensitivity in autism may lead to reduced engagement with touch information throughout childhood and may contribute to disruption in development of tactile processing over time. This inference is also in line with studies suggesting that differences between autistic and NT individuals increase with age (Gaetz et al., 2020; Lozier et al., 2014). Alternatively, the general absence of autism-related differences in early and mid-latency SEP responses may be attributed to heterogeneity in the phenotypic presentation of autism (Marco et al., 2011). Even though our sample of young children had a relatively narrow chronological age range (3-6 years), there were considerable variations in autism tactile symptomatology, which possibly obscured meaningful information.

However, we did find significant differences in later neural responses between autistic and NT children. Somewhat unexpectedly, children with autism exhibited a shorter peak latency of the N140 response ( $10 \mathrm{~ms}$ ) in somatosensory cortex, with the mechanism underlying this faster processing speed being unclear. At a physiological level, the latency difference between young autistic and NT children might indicate changes in the underlying neural circuits generating this response in the secondary somatosensory cortex (Allison et al., 1992; Roberts et al., 2020) and/or a shifted excitation-inhibition balance towards hyper-excitability (Rubenstein and Merzenich, 2003). Alternatively (or concomitantly), the N140 has been associated with cognitive functions, such as attention and conscious stimulus perception (Auksztulewicz et al., 2012; Desmedt and Tomberg, 1989; Forschack et al., 2020; Schubert et al., 2006) and hence, one might argue that the latency abnormality could be an electrophysiological correlate of "overfocused" attention, possibly due to hyper-arousal (Liss et al., 2006; Marco et al., 2011).

Interestingly, when regrouping individuals based on behavioral tactile sensitivity, we continue to find latency and amplitude differences for the N140 response (e.g., shorter and less negative in the tactile sensitive group), but also earlier responses between the tactile sensitive and the tactile normal group. Although these exploratory analyses using tactile phenotype as a grouping variable did not survive correction for multiple comparisons, they lend support to the idea of considering where individuals fall on the spectrum of a behavioral trait, rather than a specific diagnosis, to identify unique neurophysiological differences (Mihailov et al., 2020).

A small number of studies have reported links between somatosensory responses and tactile features in children and adolescents with autism (Cascio et al., 2015; Marco et al., 2012). We also found associations between our neural measures and parent-reported "real-world" behavioral responses to touch in early childhood, with autistic and NT children showing opposite patterns. In autistic children, an 
enhanced early neural response (specifically the P50) related to more tactile sensitivity, while it was associated with less behavioral tactile sensitivity in NT children. The association in the NT group should be interpreted cautiously, however, since tactile sensitivity was infrequent (e.g., less variance) in the NT group (9\%) relative to the AS (57\%) group. Interestingly, the observed brain-behavior association in the AS group suggests that low-level somatosensory cortex processing measures may be indices of tactile sensitivity in children with autism. However, the specificity of this neurophysiological observation to autism is unclear. While tactile sensitivity is frequent in autism, it is also relatively common in other disorders with altered sensory function, such as ADHD (Ben-Sasson et al., 2014; Puts et al., 2017) and Tourette's syndrome (Cox et al., 2018; Puts et al., 2015). Hence, further work is needed to examine whether the association between early neural responses to touch and tactile sensitivity is autism-specific or generalizes across disorders with altered tactile processing.

Of note, enhanced neural responsiveness to touch seemed to be related to hypo-sensitivity, rather than hyper-sensitivity in autism. Although the association with tactile hypo-sensitivity fell short of corrected significance, this finding lends some support to the idea that these two opposing behavioral profiles do not share a common underlying neural mechanism (Cascio et al., 2015). In addition, these behavioral profiles were highly correlated across the entire sample, but not within the AS group, further supporting the divergent mechanism assertion. While individuals exhibiting hyper-sensitivity show exaggerated or avoidant responses to sensory stimuli (e.g., distress to grooming activities or wearing clothes), hyposensitivity is characterised by an absence of or diminished/delayed response to sensory stimuli (e.g., unaware or slow to respond to touch or pain) (Ben-Sasson et al., 2009).

In general, there is a paucity of neuroimaging studies on individuals with autism with intellectual and verbal disabilities, due to methodological challenges stemming from participants' difficulties tolerating research protocols (Jack and Pelphrey, 2017; Tager-Flusberg and Kasari, 2013). In this study, we thus purposefully employed a passive tactile EEG task that did not require semantic and pragmatic comprehension nor an overt response to the tactile stimulation. Further, we individually tailored the testing environment and employed behavioral strategies to increase compliance. As a result, we were able to collect EEG data from $>80 \%$ of children with autism ( $>95 \%$ of NT children), including those with low cognitive and/or verbal abilities (non-verbal IQ range of 49-144). Although, this approach increases sample heterogeneity, it is in line with recent commentaries calling for the inclusion of historically understudied populations within autism (Jack and Pelphrey, 2017), and offers a pathway towards more generalizable conclusions about autism.

\section{Limitations}

Several limitations of the study have to be recognized. The current study predominantly focused on the somatosensory cortex, due to its crucial role in tactile information processing (Delhaye et al., 2018). However, other systems, including attentional and emotional responses to tactile input warrant further exploration (e.g., using multimodal approaches) as it is likely that multiple related processes lead to differences in tactile function in autism. One must also consider that brief tactile stimuli to the glabrous 
skin provide only discriminative touch information, but not affective and rewarding properties of touch. C tactile (CT) afferents, which innervate hairy skin, are thought to be related to affective responses to tactile stimuli and pain (McGlone et al., 2014; Olausson et al., 2002) and might be involved in activating brain regions implicated in autism (Kaiser et al., 2016; Voos et al., 2013). It will therefore be of crucial importance for future studies to utilise both types of touch to provide a comprehensive understanding of tactile processing in individuals on the autism spectrum. Lastly, we acknowledge that our sample size was somewhat small and may have limited the power to detect subtle group differences and associations. However, imaging data collection in young children under the age of 6 years and, in particular with neurodevelopmental disorders, remains a formidable challenge, and thus, this study serves as an important step for advancing our knowledge about the neural mechanisms underlying behavioral tactile sensitivity in early childhood autism.

\section{Conclusions}

These findings offer insight into the neurophysiological mechanisms underlying tactile sensitivity in early childhood autism. Findings suggest that some neural responses during tactile processing are altered in young children with autism and that tactile phenotype may associate with neurophysiological differences. Further, the association between early neural responses and behavioral tactile sensitivity suggests that accessible measurements of tactile cortical processing may be indices of tactile sensitivity in young children on the autism spectrum, which may have clinical implications. Future studies in children with autism should investigate the developmental trajectory of tactile processing taking into account tactile features frequently displayed by these children.

\section{Abbreviations}

ADHD

Attention-Deficit/Hyperactivity Disorder ADOS

Autism Diagnostic Observation Schedule

AS

Autism Spectrum

$\mathrm{Cl}$

Confidence Interval

CSP-2

Child Sensory Profile 2

EEG

Electroencephalography

FDR

False Discovery Rate

GDT 
Global Developmental Delay

HICCUP

Healthy Infants and Children Clinical Research Program

IC

Independent Component

ICA

Independent Component Analysis

$|S|$

Inter-Stimulus Interval

NT

NeuroTypical

$\mathrm{ROI}$

Region Of Interest

SRS-2

Social Responsiveness Scale, Second Edition

SEP

Somatosensory-Evoked Potential

TS

Tactile Sensitive

TT

Tactile Typical

WNV

Wechsler Non-Verbal Scale of Ability

\section{Declarations}

Ethics approval and consent to participate

The study was approved by the University of Calgary Conjoint Health Research Ethics Board (REB160576). Written informed consent in accordance with the Declaration of Helsinki was obtained from parent/guardian of each child who themselves assented to testing.

Consent for publication

Not applicable

Availability of data and materials

The datasets generated and analysed during the current study are available from the corresponding author (S.E.) upon reasonable request.

Competing interests 
There is no conflict of interest.

\section{Funding}

This work was supported by the Owerko Centre at the Alberta Children's Hospital Research Institute; the Mathison Centre for Mental Health Research and Education Postdoctoral Fellowship; the Canadian Open Neuroscience Platform (CONP) Research Scholar Award (S.E.); the Hotchkiss Brain Institute (S.B.); Natural Sciences and Engineering Research Council of Canada (S.B. and A.D.H.); the Sick Kids Foundation (A.D.H.); the Alberta Children's Hospital Research Institute; and the University of Calgary URGC (A.D.H., D.D.).

\section{Author's contributions}

S.E., C.MM., K.M., D.D., A.B.P., A.MC., S.B., and A.D.H. were involved in conceptualization and design of study. S.E., K.G., S.K., and C.W. were involved in data acquisition. S.E. and M.R. were involved in data analysis. S.E., F.C., S.B., and A.D.H. were involved in data interpretation. S.E., S.B., and A.D.H. were involved in writing and editing of the manuscript. S.B. and A.D.H. were involved in supervision and funding acquisition. All authors read and approved the manuscript.

\section{Acknowledgements}

We thank all participants who took part in this study and, in particular, our autistic participants and their parents/guardians who, with their interest and dedication, make autism research possible.

\section{References}

1. Allison T, Hume AL, Wood CC, Goff WR. Devlopment and aging changes in somatosensory, auditory and visual evoked potentials. Electroencephalogr Clin Neurophysiol. 1984;58:14-24.

2. Allison T, McCarthy G, Wood CC. The relationship between human long-latency somatosensory evoked potentials recorded from the cortical surface and from the scalp. Electroencephalogr Clin Neurophysiol Evoked Potentials. 1992. https://doi.org/10.1016/0168-5597(92)90082-M.

3. Allison T, McCarthy G, Wood CC, Darcey TM, Spencer DD, Williamson PD. Human cortical potentials evoked by stimulation of the median nerve. I. Cytoarchitectonic areas generating short-latency activity. J Neurophysiol. 1989a. https://doi.org/10.1152/jn.1989.62.3.694.

4. Allison T, Mccarthy G, Wood CC, Jones SJ. 1991. Potentials evoked in human and monkey cerebral cortex by stimulation of the median nerve: A review of scalp and intracranial recordings. Brain. https://doi.org/10.1093/brain/114.6.2465.

5. Allison T, McCarthy G, Wood CC, Williamson PD, Spencer DD. Human cortical potentials evoked by stimulation of the median nerve. II. Cytoarchitectonic areas generating long-latency activity. J Neurophysiol. 1989b. https://doi.org/10.1152/jn.1989.62.3.711. 
6. American Psychiatric Association. 2013. American Psychiatric Association: Diagnostic and Statistical Manual of Mental Disorders Fifth Edition, Arlington.

https://doi.org/10.1176/appi.books.9780890425596.744053.

7. Andrade GN, Butler JS, Peters GA, Molholm S, Foxe JJ. Atypical visual and somatosensory adaptation in schizophrenia-spectrum disorders. Transl Psychiatry. 2016;6:e804. https://doi.org/10.1038/tp.2016.63.

8. Angel RW, Quick WM, Boylls CC, Weinrich M, Rodnitzky RY. Decrement of Somatosensory Evoked Potentials During Repetitive Stimulation. Electroencephalogr Clin Neurophysiol. 1985;60:335-42.

9. Auksztulewicz R, Spitzer B, Blankenburg F. Recurrent neural processing and somatosensory awareness. J Neurosci. 2012. https://doi.org/10.1523/JNEUROSCI.3974-11.2012.

10. Ben-Sasson A, Hen L, Fluss R, Cermak SA, Engel-Yeger B, Gal E. A meta-analysis of sensory modulation symptoms in individuals with autism spectrum disorders. J Autism Dev Disord. 2009;39:1-11. https://doi.org/10.1007/s10803-008-0593-3.

11. Ben-Sasson A, Soto TW, Heberle AE, Carter AS, Briggs-Gowan MJ. Early and Concurrent Features of ADHD and Sensory Over-Responsivity Symptom Clusters. J Atten Disord. 2014. https://doi.org/10.1177/1087054714543495.

12. Benjamini Y, Hochberg Y. Controlling the False Discovery Rate: A Practical and Powerful Approach to Multiple Testing. J R Stat Soc Ser B. 1995. https://doi.org/10.1111/j.2517-6161.1995.tb02031.x.

13. Boor R, Goebel B. Maturation of near-field and far-field somatosensory evoked potentials after median nerve stimulation in children under 4 years of age. Clin Neurophysiol. 2000;111:1070-81. https://doi.org/10.1016/S1388-2457(00)00262-5.

14. Bruyant $P$, García-Larrea $L$, Mauguière $F$. Target side and scalp topography of the somatosensory P300. Electroencephalogr Clin Neurophysiol Evoked Potentials. 1993. https://doi.org/10.1016/01685597(93)90036-0.

15. Cascio C, McGlone F, Folger S, Tannan V, Baranek G, Pelphrey KA, Essick G. Tactile perception in adults with autism: A multidimensional psychophysical study. J Autism Dev Disord. 2008. https://doi.org/10.1007/s10803-007-0370-8.

16. Cascio CJ. Somatosensory processing in neurodevelopmental disorders. J Neurodev Disord. 2010;2:62-9. https://doi.org/10.1007/s11689-010-9046-3.

17. Cascio CJ, Gu C, Schauder KB, Key AP, Yoder P. Somatosensory event-related potentials and association with tactile behavioral responsiveness patterns in children with ASD. Brain Topogr. 2015;28:895-903. https://doi.org/10.1016/j.physbeh.2017.03.040.

18. Cascio CJ, Moana-filho EJ, Guest S, Nebel MB, Baranek GT, Essick GK. Perceptual and neural response to affective tactile texture stimulation in adults with autism spectrum disorders. Autism Res. 2012;5:231-44. https://doi.org/10.1002/aur.1224.Perceptual.

19. Charman T. Editorial: Trials and Tribulations in Early Autism Intervention Research. J Am Acad Child Adolesc Psychiatry. 2019. https://doi.org/10.1016/j.jaac.2019.03.004. 
20. Chaumon M, Bishop DVM, Busch NA. A practical guide to the selection of independent components of the electroencephalogram for artifact correction. J Neurosci Methods. 2015;250:47-63. https://doi.org/10.1016/j.jneumeth.2015.02.025.

21. Constantino JN, Gruber CP. 2005. Social Responsiveness Scale, in: Psychological, W, editor,. Los Angeles, CA.

22. Coskun MA, Loveland KA, Pearson DA, Papanicolaou AC, Sheth BR. Interaction of finger representations in the cortex of individuals with autism: a functional window into cortical inhibition. Autism Res. 2013;6:542-9. https://doi.org/10.1038/jid.2014.371.

23. Coskun MA, Varghese L, Reddoch S, Castillo EM, Pearson DA, Loveland KA, Papanicolaou AC, Sheth BR. How somatic cortical maps differ in autistic and typical brains. Neuroreport. 2009;20:175-9. https://doi.org/10.1097/WNR.0b013e32831f47d1.

24. Cox JH, Seri S, Cavanna AE. Sensory aspects of Tourette syndrome. Neurosci Biobehav Rev. 2018. https://doi.org/10.1016/j.neubiorev.2018.03.016.

25. Dawson G. Early behavioral intervention, brain plasticity, and the prevention of autism spectrum disorder. Dev Psychopathol. 2008;20:775-803. https://doi.org/10.1017/S0954579408000370.

26. Dawson G, Jones EJH, Merkle K, Venema K, Lowy R, Faja S, Kamara D, Murias M, Greenson J, Winter $J$, Smith M, Rogers SJ, Webb SJ. Early behavioral intervention is associated with normalized brain activity in young children with autism. J Am Acad Child Adolesc Psychiatry. 2012. https://doi.org/10.1016/j.jaac.2012.08.018.

27. Delhaye BP, Long KH, Bensmaia SJ. Neural Basis of Touch and Proprioception in Primate Cortex. Compr Physiol. 2018. https://doi.org/10.1002/cphy.c170033.

28. Delorme A, Makeig S. EEGLAB: an open source toolbox for analysis of single-trial EEG dynamics including independent component analysis. J Neurosci Methods. 2004. https://doi.org/10.1016/j.jneumeth.2003.10.009.

29. Demopoulos C, Yu N, Tripp J, Mota N, Brandes-Aitken AN, Desai SS, Hill SS, Antovich AD, Harris J, Honma S, Mizuiri D, Nagarajan SS, Marco EJ. Magnetoencephalographic imaging of auditory and somatosensory cortical responses in children with autism and sensory processing dysfunction. Front Hum Neurosci. 2017;11:1-15. https://doi.org/10.3389/fnhum.2017.00259.

30. Desmedt JE, Robertson D. Differential enhancement of early and late components of the cerebral somatosensory evoked potentials during forced-paced cognitive tasks in man. J Physiol. 1977. https://doi.org/10.1113/jphysiol.1977.sp012025.

31. Desmedt JE, Tomberg C. 1989. Mapping early somatosensory evoked potentials in selective attention: critical evaluation of control conditions used for titrating by difference the cognitive P30, P40, P100 and N140. Electroencephalogr. Clin. Neurophysiol. Evoked Potentials. https://doi.org/10.1016/0168-5597(89)90001-4.

32. DiStefano C, Dickinson A, Baker E, Spurling Jeste S. EEG data collection in children with ASD: The role of state in data quality and spectral power. Res Autism Spectr Disord. 2019;57:132-44. https://doi.org/10.1016/j.rasd.2018.10.001. 
33. Dunn W. The sensory profile: User's manual. San Antonio: Psychological Corporation; 1999.

34. Espenhahn S, Yan T, Beltrano W, Kaur S, Godfrey K, Cortese F, Bray S, Harris AD. The effect of moviewatching on electroencephalographic responses to tactile stimulation. Neuroimage. 2020. https://doi.org/10.1016/j.neuroimage.2020.117130.

35. Forschack N, Nierhaus T, Müller MM, Villringer A. 2020. Dissociable neural correlates of stimulation intensity and detection in somatosensation. Neuroimage 217. https://doi.org/10.1016/j.neuroimage.2020.116908.

36. Foss-Feig JH, Heacock JL, Cascio CJ. Tactile responsiveness patterns and their association with core features in autism spectrum disorders. Res Autism Spectr Disord. 2012;6:337-44. https://doi.org/10.1016/j.rasd.2011.06.007.TACTILE.

37. Gabrielsen TP, Anderson JS, Stephenson KG, Beck J, King JB, Kellems R, Top DN, Russell NCC, Anderberg E, Lundwall RA, Hansen B, South M. Functional MRI connectivity of children with autism and low verbal and cognitive performance. Mol Autism. 2018;9:1-14. https://doi.org/10.1186/s13229-018-0248-y.

38. Gaetz W, Jurkiewicz MT, Kessler SK, Blaskey L, Schwartz ES, Roberts TPL. Neuromagnetic responses to tactile stimulation of the fingers: Evidence for reduced cortical inhibition for children with Autism Spectrum Disorder and children with epilepsy. Neurolmage Clin. 2017;16:624-33. https://doi.org/10.1016/j.nicl.2017.06.026.

39. Gaetz W, Rhodes E, Bloy L, Blaskey L, Jackel CR, Brodkin ES, Waldman A, Embick D, Hall S, Roberts TPL. Evaluating motor cortical oscillations and age-related change in autism spectrum disorder. Neuroimage. 2020;207:116349. https://doi.org/10.1016/j.neuroimage.2019.116349.

40. Ganesan S, Khan S, Garel KLA, Hämäläinen MS, Kenet T. Normal evoked response to rapid sequences of tactile pulses in autism spectrum disorders. Front Hum Neurosci. 2016;10:1-7. https://doi.org/10.3389/fnhum.2016.00433.

41. Green SA, Hernandez L, Tottenham N, Krasileva K, Bookheimer SY, Dapretto M. Neurobiology of sensory overresponsivity in youth with autism spectrum disorders. JAMA Psychiatry. 2015. https://doi.org/10.1001/jamapsychiatry.2015.0737.

42. Güçlü B, Tanidir C, Mukaddes NM, Ünal F. Tactile sensitivity of normal and autistic children. Somatosens Mot Res. 2007;24:21-33. https://doi.org/10.1080/08990220601179418.

43. Hämäläinen $H$, Kekoni J, Sams M, Reinikainen K, Näätänen R. Human somatosensory evoked potentials to mechanical pulses and vibration: contributions of SI and SII somatosensory cortices to P50 and P100 components. Electroencephalogr Clin Neurophysiol. 1990. https://doi.org/10.1016/0013-4694(90)90148-D.

44. Jack A, Pelphrey KA. Annual Research Review: Understudied populations within the autism spectrum - current trends and future directions in neuroimaging research. J Child Psychol Psychiatry Allied Discip. 2017. https://doi.org/10.1111/jcpp.12687.

45. Kaiser MD, Yang DYJ, Voos AC, Bennett RH, Gordon I, Pretzsch C, Beam D, Keifer C, Eilbott J, McGlone F, Pelphrey KA. Brain Mechanisms for Processing Affective (and Nonaffective) Touch Are Atypical in 
Autism. Cereb Cortex. 2016. https://doi.org/10.1093/cercor/bhv125.

46. Kastner-Koller U, Deimann P, Bruckner J. Assessing handedness in pre-schoolers: Construction and initial validation of a hand preference test for 4-6-year-olds. Psychol Sci Vol. 2007;49:239-54.

47. Kenny L, Hattersley C, Molins B, Buckley C, Povey C, Pellicano E. Which terms should be used to describe autism? Perspectives from the UK autism community. Autism. 2016;20:442-62. https://doi.org/10.1177/1362361315588200.

48. Khan S, Hashmi JA, Mamashli F, Bharadwaj HM, Ganesan S, Michmizos KP, Kitzbichler MG, Zetino M, Garel KLA, Hämäläinen MS, Kenet T. 2016. Altered onset response dynamics in somatosensory processing in autism spectrum disorder. Front Neurosci 10.

https://doi.org/10.3389/fnins.2016.00255.

49. Khan S, Michmizos K, Tommerdahl M, Ganesan S, Kitzbichler MG, Zetino M, Garel KLA, Herbert MR, Hämäläinen MS, Kenet T. Somatosensory cortex functional connectivity abnormalities in autism show opposite trends, depending on direction and spatial scale. Brain. 2015;138:1394-409. https://doi.org/10.1093/brain/awv043.

50. Landa RJ. Efficacy of early interventions for infants and young children with, and at risk for, autism spectrum disorders. Int Rev Psychiatry. 2018. https://doi.org/10.1080/09540261.2018.1432574.

51. Leekam SR, Nieto C, Libby SJ, Wing L, Gould J. Describing the sensory abnormalities of children and adults with autism. J Autism Dev Disord. 2007;37:894-910. https://doi.org/10.1007/s10803-0060218-7.

52. Liss M, Saulnier C, Fein D, Kinsbourne M. Sensory and attention abnormalities in autistic spectrum disorders. Autism. 2006;10:155-72. https://doi.org/10.1177/1362361306062021.

53. Lopez-Calderon J, Luck SJ. 2014. ERPLAB: an open-source toolbox for the analysis of event-related potentials. Front Hum Neurosci 8. https://doi.org/10.3389/fnhum.2014.00213.

54. Lord C, Risi S, Lambrecht L, Cook EH, Leventhal BL, Dilavore PC, Pickles A, Rutter M. The Autism Diagnostic Observation Schedule-Generic: A standard measure of social and communication deficits associated with the spectrum of autism. J Autism Dev Disord. 2000. https://doi.org/10.1023/A:1005592401947.

55. Lozier LM, Vanmeter JW, Marsh AA. Impairments in facial affect recognition associated with autism spectrum disorders: A meta-analysis. Dev Psychopathol. 2014;26:933-45. https://doi.org/10.1017/S0954579414000479.

56. Marco EJ, Hinkley LBN, Hill SS, Nagarajan SS. Sensory processing in autism: A review of neurophysiologic findings. Pediatr Res. 2011;69:48-54. https://doi.org/10.1203/PDR.0b013e3182130c54.

57. Marco EJ, Khatibi K, Hill SS, Siegel B, Arroyo MS, Dowling AF, Neuhaus JM, Sherr EH, Hinkley LN, Nagarajan SS. Children with autism show reduced somatosensory response: an MEG study. Autism Res. 2012;5:340-51. https://doi.org/10.1038/jid.2014.371.

58. McCormick C, Hepburn S, Young GS, Rogers SJ. Sensory symptoms in children with autism spectrum disorder, other developemntal disorders and typical development: A longitudinal study. Autism. 
2016;20:572-9. https://doi.org/10.1177/0038040711417011.Competitive.

59. McGlone F, Wessberg J, Olausson H. 2014. Discriminative and Affective Touch: Sensing and Feeling. Neuron. https://doi.org/10.1016/j.neuron.2014.05.001.

60. Mihailov A, Philippe C, Gloaguen A, Grigis A, Laidi C, Piguet C, Houenou J, Frouin V. Cortical signatures in behaviorally clustered autistic traits subgroups: a population-based study. Transl Psychiatry. 2020. https://doi.org/10.1038/s41398-020-00894-3.

61. Miyazaki M, Fujii E, Saijo T, Mori K, Hashimoto T, Kagami S, Kuroda Y. Short-latency somatosensory evoked potentials in infantile autism: Evidence of hyperactivity in the right primary somatosensory area. Dev Med Child Neurol. 2007;49:13-7. https://doi.org/10.1017/S0012162207000059.x.

62. Naglieri JA, Brunnert K. 2009. Wechsler Nonverbal Scale of Ability (WNV), in: Practitioner's Guide to Assessing Intelligence and Achievement. https://doi.org/10.1007/978-0-387-79061-9_3067.

63. Olausson H, Lamarre Y, Backlund H, Morin C, Wallin BG, Starck G, Ekholm S, Strigo I, Worsley K, Vallbo B, Bushnell MC. Unmyelinated tactile afferents signal touch and project to insular cortex. Nat Neurosci. 2002. https://doi.org/10.1038/nn896.

64. Pihko E, Nevalainen P, Stephen J, Okada Y, Lauronen L. Maturation of somatosensory cortical processing from birth to adulthood revealed by magnetoencephalography. Clin Neurophysiol. 2009;120:1552-61. https://doi.org/10.1016/j.clinph.2009.05.028.

65. Polich J. Updating P300: An integrative theory of P3a and P3b. Clin. 2007;118:2128-48. https://doi.org/10.1016/j.clinph.2007.04.019.Updating.

66. Puts NAJ, Harris AD, Crocetti D, Nettles C, Singer HS, Tommerdahl M, Edden RAE, Mostofsky SH. Reduced GABAergic inhibition and abnormal sensory symptoms in children with Tourette syndrome. J Neurophysiol. 2015. https://doi.org/10.1152/jn.00060.2015.

67. Puts NAJ, Harris AD, Mikkelsen M, Tommerdahl M, Edden RA, Mostofsky SH. Altered tactile sensitivity in children with Attention Deficit Hyperactive Disorder. J Neurophysiol. 2017;118:2568-78. https://doi.org/10.1152/jn.00087.2017.

68. Puts NAJ, Wodka EL, Tommerdahl M, Mostofsky SH, Edden RAE. Impaired tactile processing in children with autism spectrum disorder. J Neurophysiol. 2014;111:1803-11.

69. Roberts TPL, Bloy L, Ku M, Blaskey L, Jackel CR, Edgar JC, Berman JI. 2020. A Multimodal Study of the Contributions of Conduction Velocity to the Auditory Evoked Neuromagnetic Response: Anomalies in Autism Spectrum Disorder. Autism Res. 1-16. https://doi.org/10.1002/aur.2369.

70. Robertson CE, Baron-Cohen S. Sensory perception in autism. Nat Rev Neurosci. 2017;18:671-84. https://doi.org/10.1038/nrn.2017.112.

71. Robison JE. Talking about autism-thoughts for researchers. Autism Res. 2019. https://doi.org/10.1002/aur.2119.

72. Rogers SJ, Estes A, Lord C, Munson J, Rocha M, Winter J, Greenson J, Colombi C, Dawson G, Vismara LA, Sugar CA, Hellemann G, Whelan F, Talbott M. A Multisite Randomized Controlled Two-Phase Trial of the Early Start Denver Model Compared to Treatment as Usual. J Am Acad Child Adolesc Psychiatry. 2019. https://doi.org/10.1016/j.jaac.2019.01.004. 
73. Rubenstein JLR, Merzenich MM. Model of autism: increased ratio of excitation/inhibition in key neural systems. Genes Brain Behav. 2003;2:255-67. https://doi.org/10.1046/j.1601183X.2003.00037.x.

74. Sandbank M, Bottema-Beutel K, Crowley S, Cassidy M, Dunham K, Feldman JI, Crank J, Albarran SA, Raj S, Mahbub P, Woynaroski TG. Project AIM: Autism intervention meta-analysis for studies of young children. Psychol Bull. 2020. https://doi.org/10.1037/bul0000215.

75. Schubert R, Blankenburg F, Lemm S, Villringer A, Curio G. 2006. Now you feel it - Now you don't: ERP correlates of somatosensory awareness. Psychophysiology. https://doi.org/10.1111/j.14698986.2006.00379.x.

76. Tager-Flusberg H, Kasari C. Minimally verbal school-aged children with autism spectrum disorder: The neglected end of the spectrum. Autism Res. 2013. https://doi.org/10.1002/aur.1329.

77. Tannan V, Zhang JK,H, Baranek Z, Tommerdahl G, M. Perceptual metrics of individuals with autism provide evidence for disinhibition. Autism Res. 2008;1:223-30. https://doi.org/10.1038/jid.2014.371.

78. Thye MD, Bednarz HM, Herringshaw AJ, Sartin EB, Kana RK. The impact of atypical sensory processing on social impairments in autism spectrum disorder. Dev Cogn Neurosci. 2018;29:151-67. https://doi.org/10.1016/j.den.2017.04.010.

79. Tomchek SD, Dunn W. Sensory processing in children with and without autism: a comparative study using the short sensory profile. Am J Occup Ther. 2007;61:190-200. https://doi.org/10.5014/ajot.61.2.190.

80. Tommerdahl M, Tannan V, Cascio C, Baranek G, Whitsel B. Vibrotactile adaptation fails to enhance spatial localization in adults with autism. Brain Res. 2007;1154:116-23. https://doi.org/10.1002/ana.22528.Toll-like.

81. Uppal N, Foxe JJ, Butler JS, Acluche F, Molholm S. The neural dynamics of somatosensory processing and adaptation across childhood: a high-density electrical mapping study. J Neurophysiol. 2016;115:1605-19. https://doi.org/10.1152/jn.01059.2015.

82. Vanderwal T, Kelly C, Eilbott J, Mayes LC, Xavier F. Inscapes: a movie paradigm to improve compliance in functional magnetic resonance imaging. Neuroimage. 2015;122:222-32. https://doi.org/10.1002/cncr.27633.Percutaneous.

83. Voos AC, Pelphrey KA, Kaiser MD. Autistic traits are associated with diminished neural response to affective touch. Soc Cogn Affect Neurosci. 2013. https://doi.org/10.1093/scan/nss009.

84. Wang Q, Webber RM, Stanley GB. Thalamic synchrony and the adaptive gating of information flow to cortex. Nat Neurosci. 2010;13:1534-41. https://doi.org/10.1038/nn.2670.Thalamic.

85. Wark B, Lundstrom BN, Fairhall A. Sensory adaptation. Curr Opin Neurobiol. 2008;17:423-9.

86. Zhu Y, Georgesco M, Cadilhac J. Normal latency values of early cortical somatosensory evoked potentials in children. Electroencephalogr Clin Neurophysiol Evoked Potentials. 1987. https://doi.org/10.1016/0168-5597(87)90058-X.

\section{Figures}



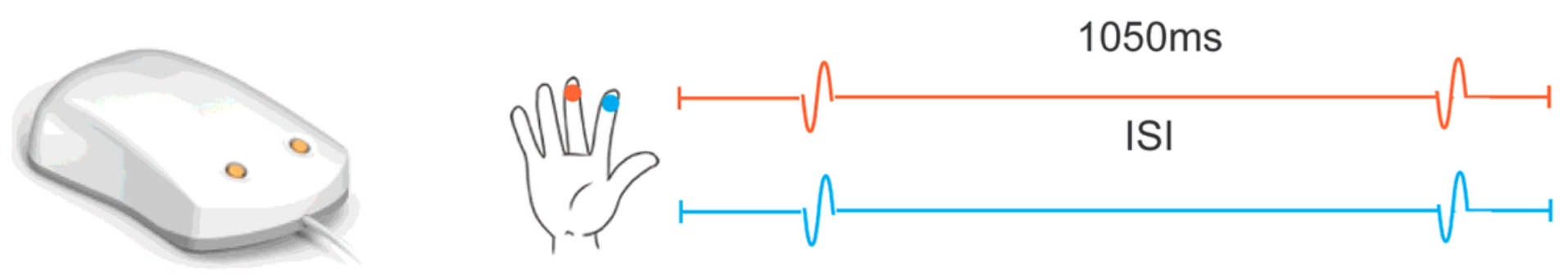

\section{short ISI}

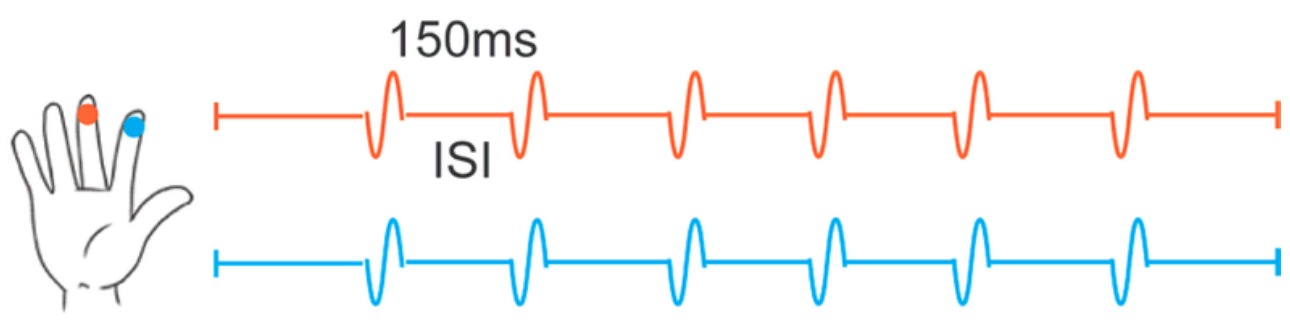

\section{Figure 1}

Tactile stimulation paradigm. A, A Brain Gauge two-digit vibrotactile stimulator was used for stimulus generation. B, Schematic of the passive tactile stimulation. Trains of 6 tactile stimuli were delivered simultaneously to the right-hand digit 2 and digit 3 . In the long ISI condition stimuli were delivered further apart in time (ISI of $1050 \mathrm{~ms}$ ), while in the short ISI condition stimuli were presented closer together (ISI of $150 \mathrm{~ms}$ ) which typically leads to a reduction in somatosensory cortex response. Each stimulus train was separated from the next by $5 \pm 0.5 \mathrm{~s}$.
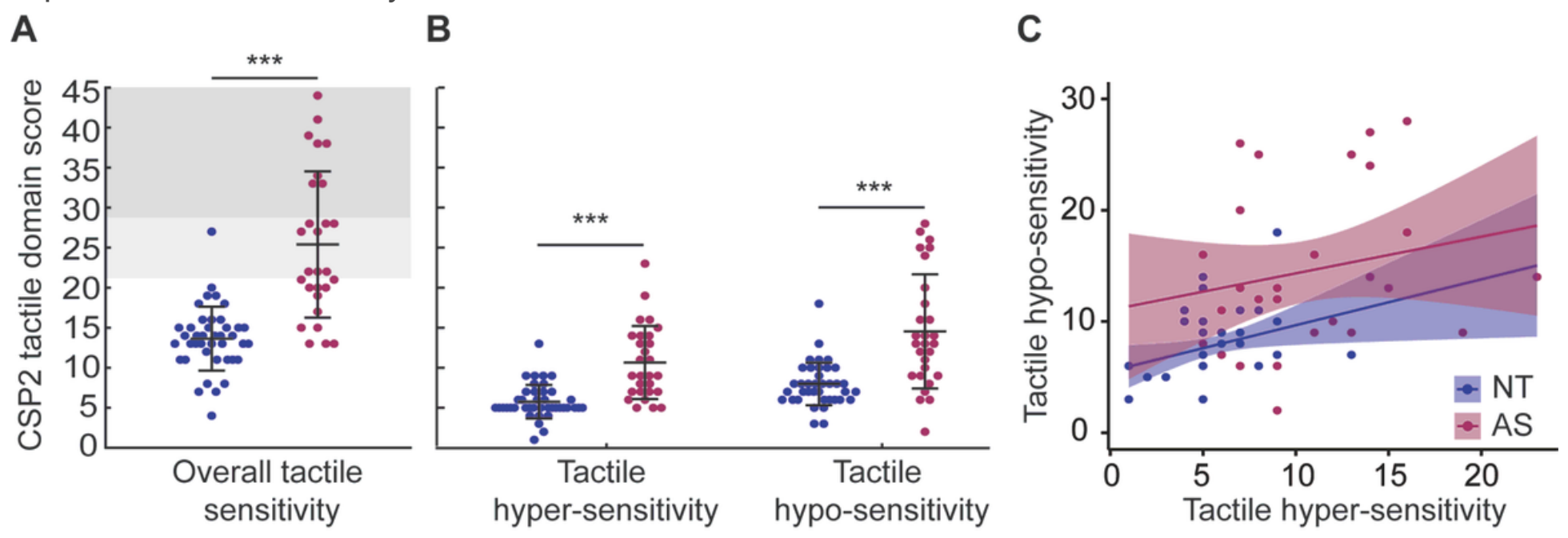

Figure 2

Behavioral tactile sensitivity in NT and autistic children. A, Scores on the CSP-2 tactile domain are shown for NT (blue) and autistic (wine red) children, showing greater overall behavioral tactile sensitivity in 
autism. Light grey shading indicates 'probable sensory differences' and dark grey shading 'definite sensory differences'. B, Tactile hyper- and hypo-sensitivity are shown for each group, with each of these behavioral profiles being the sum of different CSP-2 quadrants within the tactile domain. C, Association between tactile hyper- and hypo-sensitivity shown for each group (NT: $r=0.34, p=0.028$; AS: $r=0.21$, $p=0.281$ ). Dots represent individual participants $(A, B, C)$ and black bars represent mean $\square S D$ across participants (A, B). Shading indicates the $95 \%$ confidence interval on the partial correlations. Statistical group difference: $* \star * p<0.001$.

A contralateral somatosensory ROI
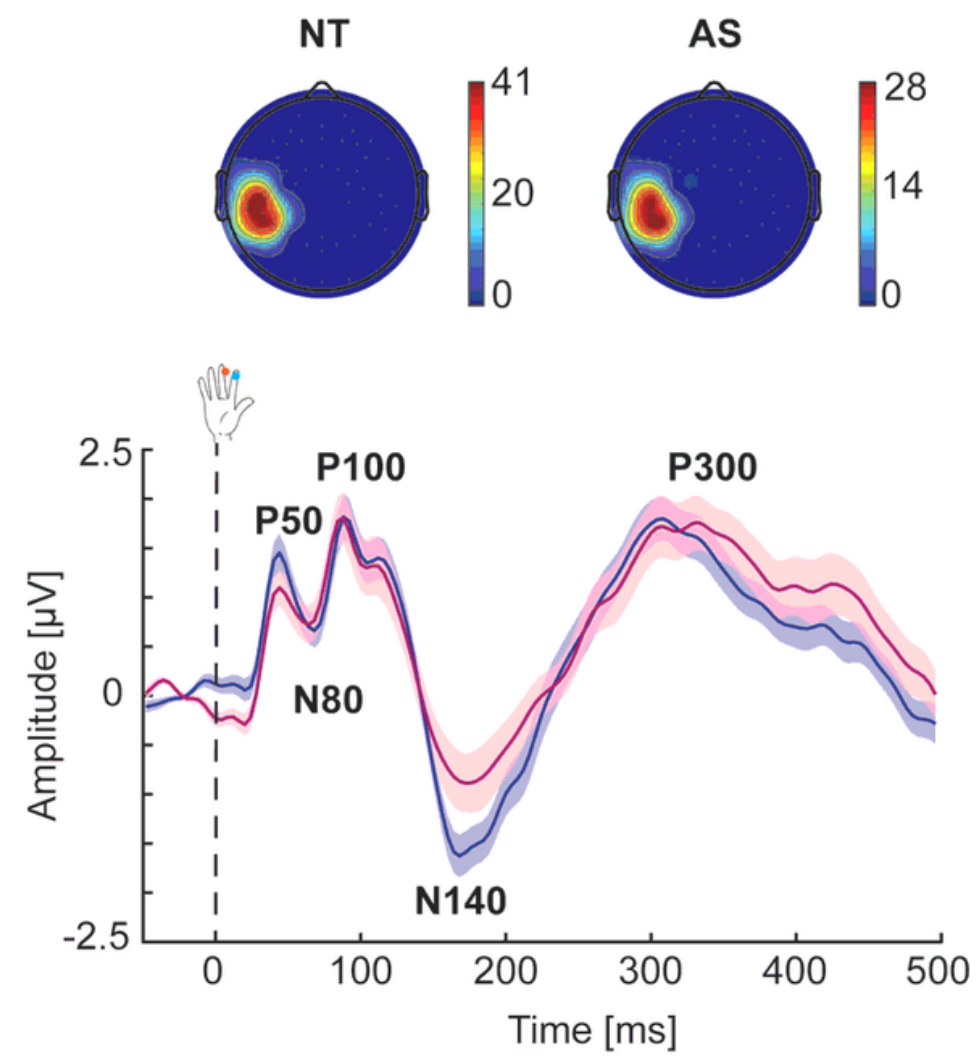

B frontocentral ROI
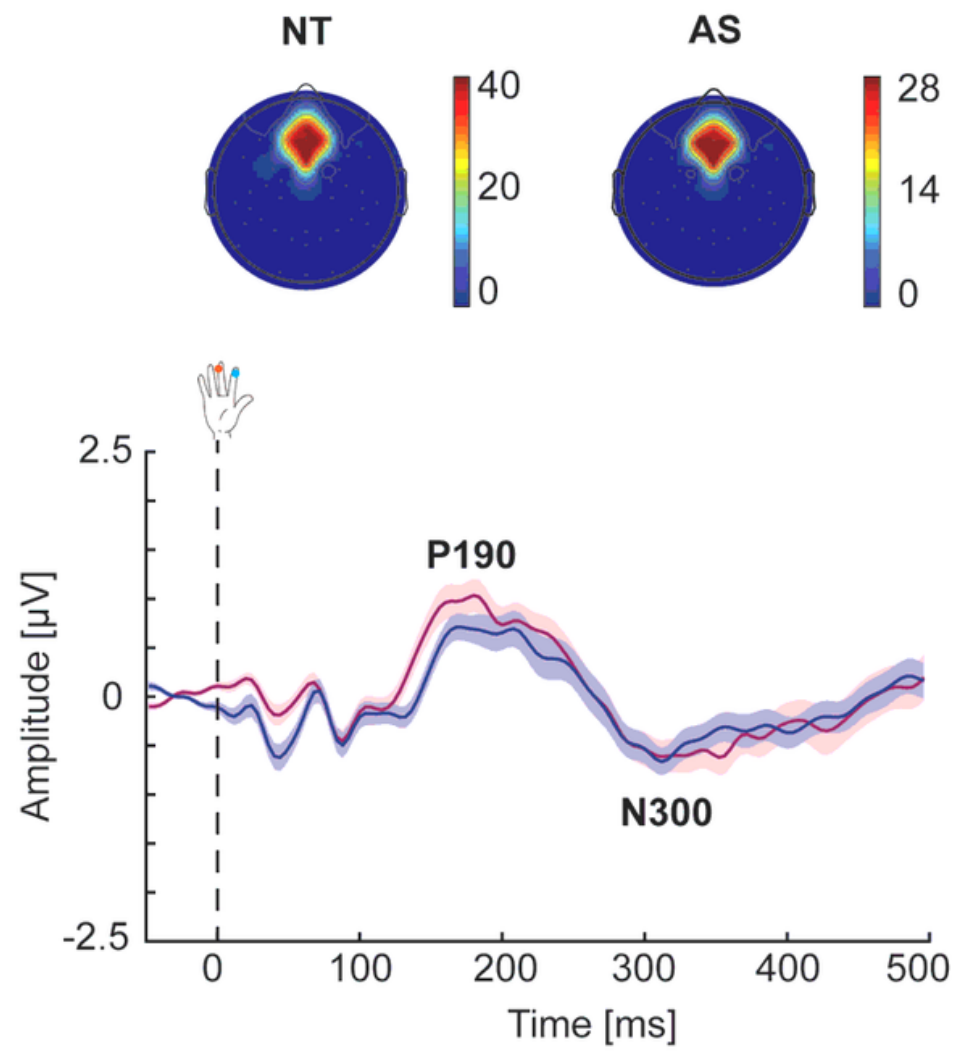

AS $\quad$ NT

C
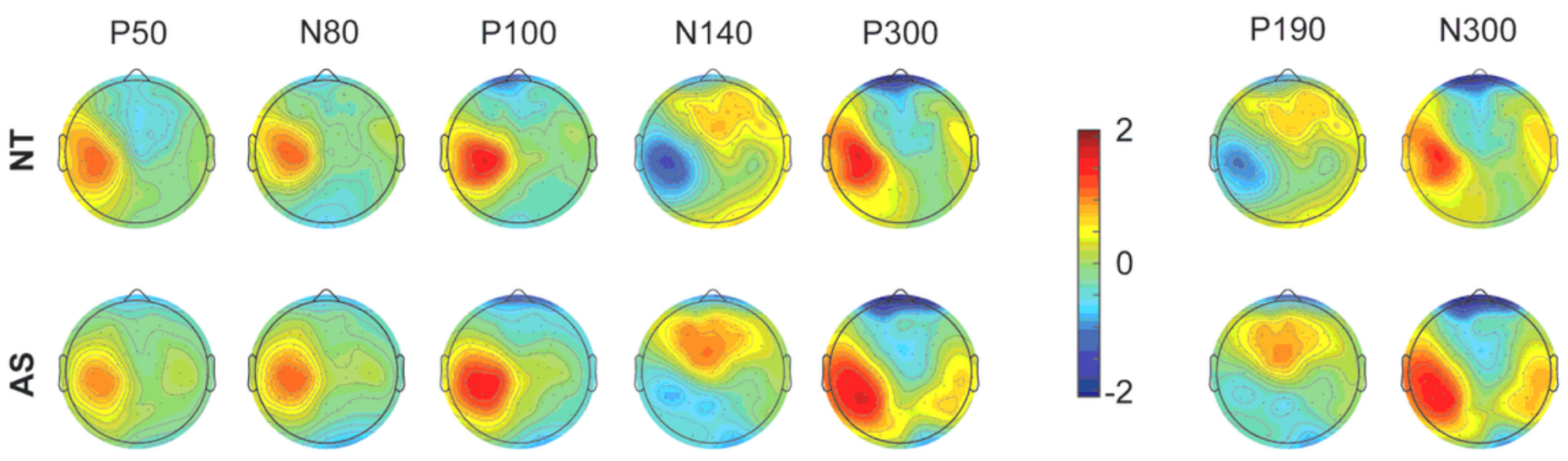

Figure 3

SEPs to passive tactile stimulation. A, B, Individual ROls over contralateral somatosensory cortex and frontocentral region were selected for each participant (top). The topographical plots show the overlap of 
selected electrodes for each group, with the color bar representing the number of participants for which that electrode (area) was selected. Grand-averaged SEP traces in response to passive tactile stimulation from ROls over the contralateral somatosensory cortex (A, bottom) and frontal cortex (B, bottom) for the NT (blue) and AS (wine red) groups for the $1050 \mathrm{~ms}$ ISI. Major SEP responses are clearly distinguishable: P50 (30-55 ms), N80 (55-80 ms), P100 (80-125 ms), N140 (150 -210 ms), P300 (270-350 ms) over somatosensory cortex as well as P190 (150-240 ms) and N300 (280-400 ms) over bilateral frontal cortex. Dashed line at time $0 \mathrm{~ms}$ indicates time of fingertip stimulation. C, Topographical plots representing neural activity averaged over the respective time windows for each SEP response show a predominantly contralateral somatosensory area activation, with frontocentral areas being activated during later processing stages. Shaded area $(A, B)$ indicates between-participant SEM.

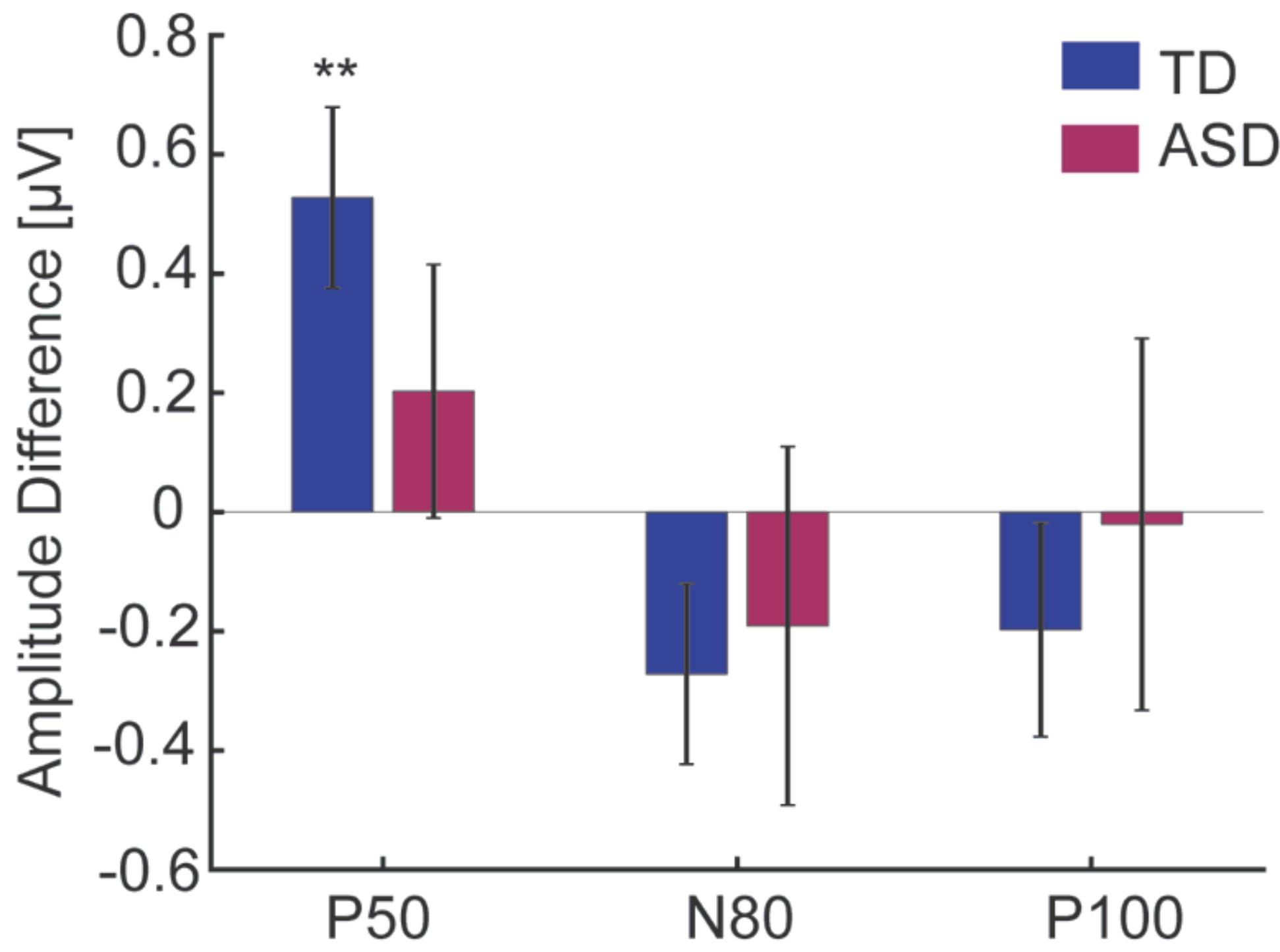

Figure 4

Somatosensory adaptation to repeated tactile stimulation. The mean amplitude difference between long and short ISI is shown for the early and mid-latency SEP responses over the contralateral somatosensory cortex for the NT (blue) and AS (wine red) groups. Note that positive values represent greater adaptation. Error bars represent between-participant SEM. Statistical difference from zero: ${ }^{* *} p<0.01$. 


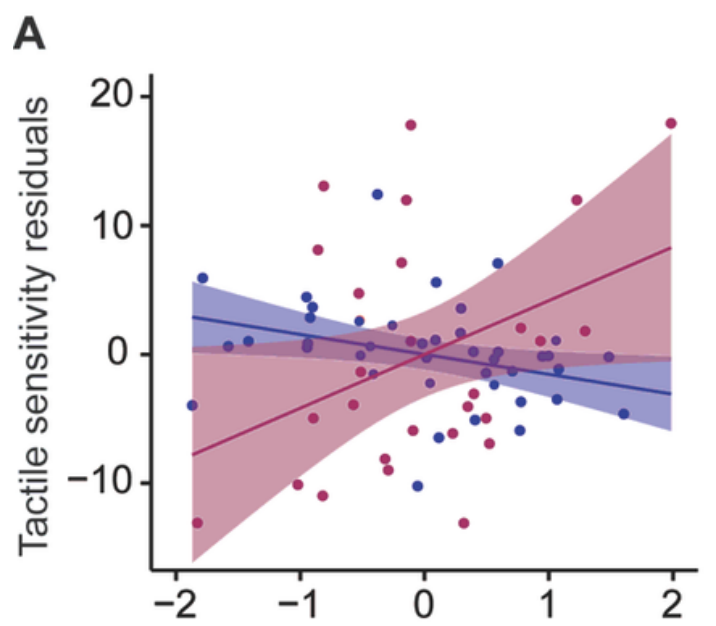

P50 amplitude residuals $[\mu \mathrm{V}]$
B

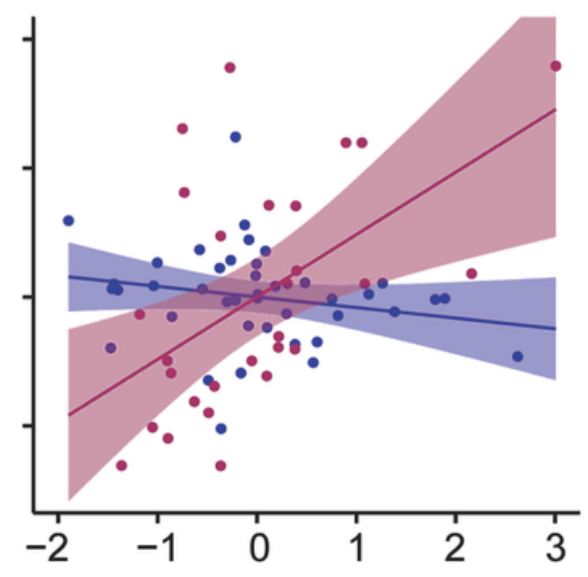

N80 amplitude residuals $[\mu \mathrm{V}]$
C

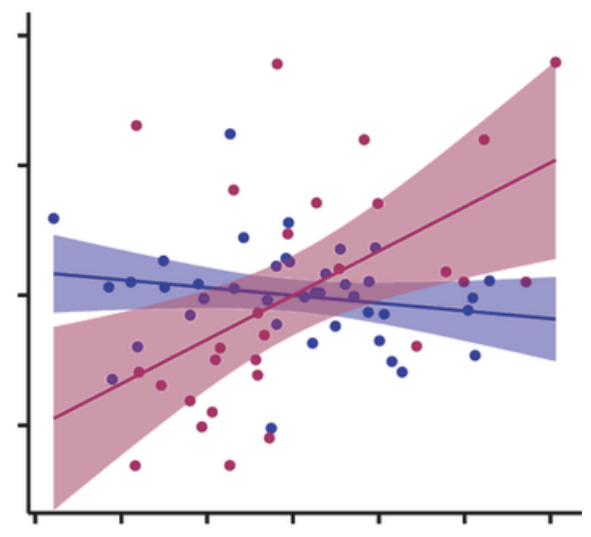

P100 amplitude residuals $[\mu \mathrm{V}]$

- AS $\quad$ NT

Ai

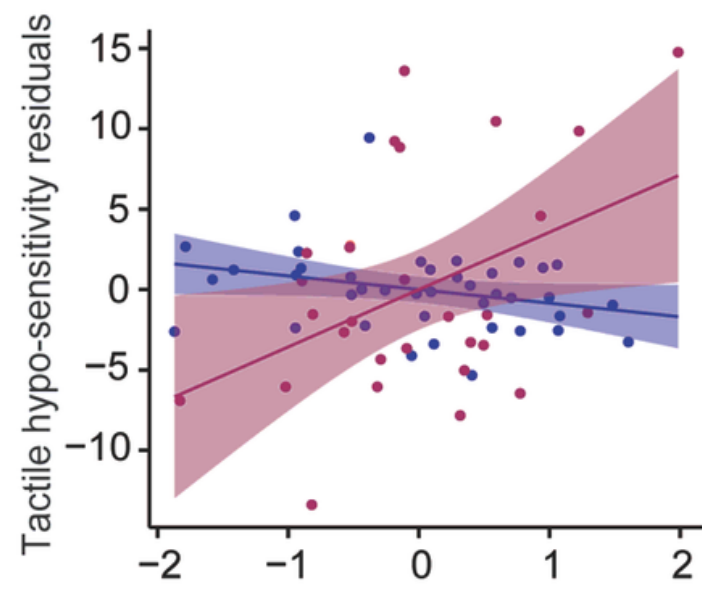

P50 amplitude residuals $[\mu \mathrm{V}]$

Ci

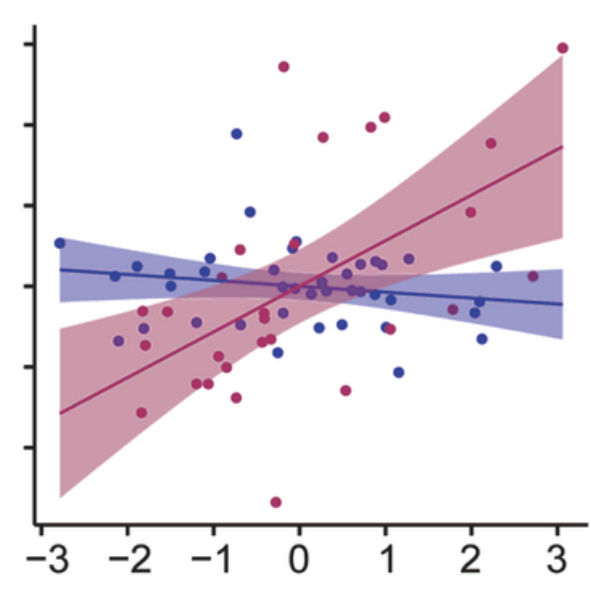

P100 amplitude residuals $[\mu \mathrm{V}]$

\section{Figure 5}

Associations between behavioral tactile sensitivity measures and SEP responses. Partial correlations are shown for significant group by tactile sensitivity interactions found in the general linear models. Positive partial correlations were observed between overall tactile sensitivity and P50 (A), N80 (B), and P100 (C) amplitude for the AS group [P50: $r=0.38, p=0.057$; N80: $r=0.53, p=0.005 ; P 100: r=0.52, p=0.007$ ], but negative (mostly non-significant) correlations for the NT group [P50: $r=-0.35, p=0.029$; N80: $r=-0.21$, $p=0.208 ; P 100: r=-0.17, p=0.297]$. Similarly, positive partial correlations were observed between tactile hypo-sensitivity specifically and P50 (Ai) and P100 (Ci) amplitude for the AS group [P50: $r=0.42, p=0.032$; P100: $r=0.60, p=0.002$ ], who showed the opposite pattern to the NT group [P50: $r=-0.32, p=0.046 ; P 100$ : $r=-0.21, p=0.209]$. All associations are controlled for age and sex. Shading indicates the $95 \%$ confidence interval on the partial correlations. 

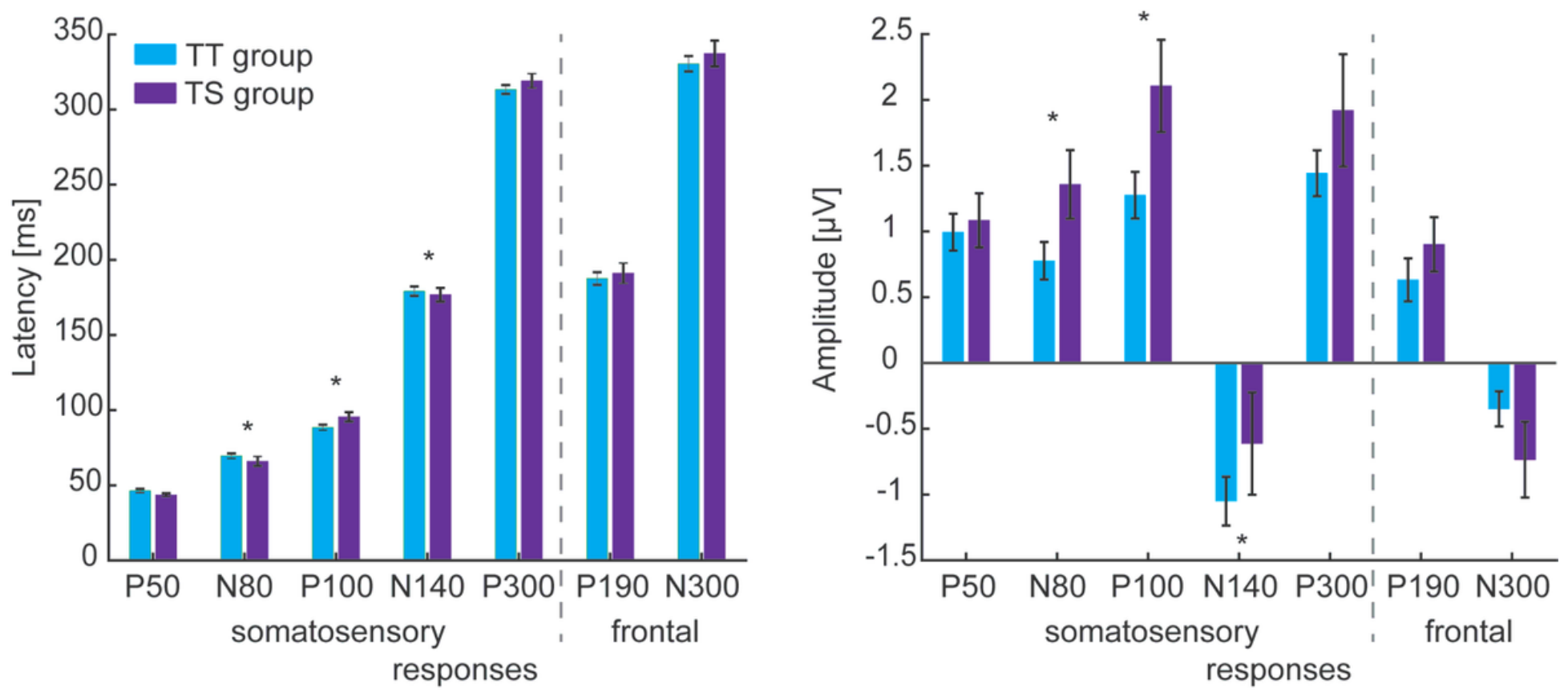

Figure 6

Average latency and amplitude of SEP responses for children with and without behavioral tactile sensitivity, independent of diagnosis. Error bars indicate between-participant SEM. * differences between tactile typical (TT, light blue) and tactile sensitive (TS, purple) groups at $p<0.05$ uncorrected that do not survive multiple comparison correction. 